Max-Planck-Institut für demografische Forschung

Max Planck Institute for Demographic Research

Konrad-Zuse-Strasse 1 - D-18057 Rostock - GERMANY

Tel +49 (0) 3812081 - 0; Fax +49 (0) 3812081 - 202;

http://www.demogr.mpg.de

MPIDR WORKING PAPER WP 2014-001

JANUARY 2014

\title{
Fertility of Turkish migrants \\ in Germany: \\ Duration of stay matters
}

Katharina Wolf (wolf@demogr.mpg.de)

This working paper has been approved for release by: Frans Willekens (willekens@demogr.mpg.de), Head of the Research Group on International Migration.

(C) Copyright is held by the authors.

Working papers of the Max Planck Institute for Demographic Research receive only limited review. Views or opinions expressed in working papers are attributable to the authors and do not necessarily reflect those of the Institute. 


\title{
Fertility of Turkish migrants in Germany: Duration of stay matters
}

\author{
Katharina Wolf
}

January 23, 2014

\begin{abstract}
This study examines the fertility behavior of male and female Turkish migrants in Germany. Our main objective in this paper is to investigate the role of duration since migration in first and higher order birth risks. We use data from the first wave of the German Generations and Gender Survey (GGS) that was conducted in 2005/06. In a first step, the age-specific fertility rates and the total fertility rates are estimated and compared for the German and the Turkish respondents following a method suggested by Toulemon (2004). Second, discrete-time hazard rate models are calculated. We find strongly elevated birth risks among the Turkish respondents in the years immediately following migration. This effect is found to be stronger for the females than for the males. The role of age at migration is also investigated. We find here that migrants who were older than age 30 at migration had significantly lower birth rates than other migrants, particularly those who migrated in young adulthood. We conclude that the fertility of Turkish migrants in Germany is strongly associated with their migration history. It is therefore important to take into account both the age at migration and the duration of stay when studying migrant fertility.
\end{abstract}

Keywords: immigrants, fertility, male fertility, life-course analysis, Germany, Turkish migrants

\section{Introduction}

In 2011, almost three million people of Turkish descent were living in Germany, representing 3.6 percent of the total population (Statistisches Bundesamt, 2012). Around half of them belong to the first generation of immigrants, and thus migrated themselves. As migration is a decisive event in the human life course, it can be expected to have a strong effect on fertility behavior. The main objective of this paper is to investigate the impact of the timing of migration on the fertility of male and female Turkish migrants in Germany. As we are interested in the migrants' fertility behavior in Turkey as well as in Germany, the children born before and after migration are considered in this analysis. Understanding 
the behavior of Turkish migrants is highly relevant in the German research context, as Turks are the largest immigrant group in the country. Labor shortages in Germany after World War II led to a rising demand for workers. In the late 1950s, guest worker programs were initiated via agreements with southern European countries. Through these programs, foreign workers were recruited to fill positions in Germany, primarily in the industrial sector (Münz et al., 1999, p. 43 ff.). Starting in 1961, low-skilled workers from Turkey entered the country, most of them young men. Since 1965, immigration for the purposes of reuniting families has been permitted. Since 1973, when the recruitment agreements were terminated, family reunion or family reunification has been the only way to enter the country. Thus, the characteristics of the migration flows from Turkey changed from being male-dominated, work-related, and temporary; to being more long-term and family-oriented, involving women and children (Bade, 1992, p. 396). The trend toward the reunion and the formation of migrant families created a growing Turkish minority group in Germany. The demographic behavior of this group has been poorly understood until very recently. Previous studies have investigated the fertility of guest worker migrants, and have found that these migrants have high fertility rates, particularly shortly after they arrive in Germany and in the early years of marriage (Mayer and Riphahn, 1999; Milewski, 2007, 2010). None of these studies focused specifically on Turkish migrants, and only the children born in Germany were taken into account. To shed light on the specific Turkish case, we have chosen in this study to examine Turkish fertility from a life course perspective. We look at each migrant's full fertility history: i.e., all of the children born to the migrant, both before and after migration, are considered. This approach allows us to study the impact of the timing of migration on fertility behavior. Unlike previous studies conducted for Germany, both Turkish men and women are studied, and their fertility behavior is compared to that of their German counterparts.

Scholars generally assume that differences between the fertility patterns of migrants and natives are the result of socialization, adaptation, disruption, or selection effects. They also assume that the events of migration, union formation, and childbirth are interrelated. To test these hypotheses, micro-level data of the German Generations and Gender Survey (GGS) are used in this paper. In a first step, age-specific fertility rates as well as total fertility rates are estimated to provide an initial impression of the differences in fertility between Turkish migrants and Germans. Both rates are displayed in groups by age at migration. In the multivariate analysis, the risk of having a child by duration of stay is examined with the help of discrete-time regression models. First, Turkish migrants are compared to their German counterparts. In a second set of models, Turkish migrants are investigated separately to allow for the inclusion of migration-specific covariates. All of the regression models are calculated separately for the transition to a first birth and to higher order births. 


\section{Theoretical considerations}

\subsection{Theoretical background}

To explain migrant fertility behavior in relation to native fertility behavior, some major "partly complementary, partly contradictory hypotheses" (Kulu, 2005, p. 52) have been advanced by demographic researchers. Scholars have variously attributed migrants' fertility behavior to socialization, adaptation, selection, or disruption effects (Hervitz, 1985; Kulu, 2005; Lee, 1992; Milewski, 2007; Rundquist and Brown, 1989; Singley and Landale, 1998; Stephen and Bean, 1992). These theories might overlap in some points, operate differently for particular groups, or apply to special periods or cases. Each of these hypotheses has been both confirmed and challenged, depending on the context, the migration type, and the time frame studied (for further details see Kulu, 2005).

Disruption theory takes into account the economic and psychological costs of migration. Because of the stresses people are exposed to during the migration process and shortly after arrival, it is assumed that there will be a short-term interruption of fertility (Goldstein, 1973; Hervitz, 1985; Kulu, 2005). Immediately after migration, people need some time to settle in, and conception is unlikely. A so-called anticipatory effect may occur if the plan to have a child is interrupted preceding the move due to anticipatory effects or a short-term separation from the partner. Both effects decrease fertility temporarily, but do not necessarily influence total fertility over the life course (Abbasi-Shavazi and McDonald, 2002).

Socialization theory emphasizes the role of childhood socialization. It assumes that the norms and values adopted in the home country are essential for the later fertility behavior of migrants (Hervitz, 1985; Kahn, 1994; Kulu, 2005; Stephen and Bean, 1992). Those norms and values are shaped during early childhood and reflect the predominant fertility behavior in the country of origin. Migrants will maintain the norms and values learned during socialization, even if they differ from the norms and values in the country of destination. As fertility behavior is primarily influenced by the fertility level in the home country, convergence effects will first appear in the second generation of migrants, who grow up in the host country, and are thus socialized by the norms and values of the host society.

Adaptation theory hypothesizes that there are differences between a migrant's country of origin and his or her country of destination in terms of cultural and socioeconomic conditions. From the point of view of New Home Economics (Becker, 1981), the differences in the economic conditions of the home and the host countries can shift the cost-benefit calculation of having children. As migrants may also undergo acculturation after spending more time in the destination country, their desired number of children might change. Thus, migrants adjust to the social, economic, and cultural conditions in the host country, and change their behavior in the long run (Kulu, 2005; Milewski, 2007). As the 
amount of time they have been in the country grows, the fertility levels of migrants are thus expected to increasingly resemble the levels of the host country natives.

Selection theory does not focus on the change in norms, but instead assumes that the individual characteristics of migrants determine their particular fertility behavior. As migrants form a select group within their home country, they may be expected to show fertility preferences closer to those of the host society (Goldstein and Goldstein, 1981; Kulu, 2005). This selectivity is based on observed characteristics like education or occupation, and unobserved characteristics like social mobility ambitions or family orientation. In addition, recent research has extended the conventional notion of selection theory, positing that selectivity might also occur with respect to the reasons for migration (Kulu and González-Ferrer, 2013, p. 13). Marriage migration, for example, generally results in elevated fertility levels immediately after migration (Andersson, 2004; Kulu, 2005; Singley and Landale, 1998).

The idea of the interrelation of events posits that several life course events may occur simultaneously because these events are connected (Andersson, 2004; Mulder and Wagner, 1993; Singley and Landale, 1998). For example, migration, union formation, and childbirth (especially the birth of the first child) are seen as interdependent, and thus as likely to occur within a short period of time. It is therefore assumed that the elevated birth rates observed among migrants shortly after arrival result from the close proximity of migration, union formation, and childbirth.

Finally, legitimacy hypothesis connects migration with the legal status of the mother and childbirth. According to that, fertility may increase shortly after migration because undocumented migrants want to obtain legal or economic benefits by giving birth (Bledsoe, 2004; Bledsoe et al., 2007). As this theory only applies to specific contexts, it is rarely used to explain general patterns of migrant fertility.

\subsection{Previous research}

Only a few of the studies on the fertility of migrants have taken a life course perspective; i.e., fertility in the host country as well as in the home country was considered (Alders, 2000; Devolder and Bueno, 2011; Toulemon, 2004). There are two studies that compared migrant fertility behavior to that of French (Toulemon, 2004) and Catalan (Devolder and Bueno, 2011) natives. Both found distinctive arrival effects; i.e., the birth risks of the migrants were elevated relative to those of the natives during the years immediately following migration. With increasing duration of stay, the migrant fertility risks decreased and converged to native levels. Furthermore, the age at migration has been shown to play a major role in explaining migrant fertility. For France and Catalonia, the arrival effect was found to be particularly high among migrants who arrived during young adulthood. Those migrating during childhood more closely resembled the natives in terms of their fertility patterns. An anticipatory effect i.e., a very low fertility risk in the years immediately preceding migration - was 
most visible among the women who migrated between the ages of 25 and 30 . For France, migrant fertility levels were found to be very similar to French levels before migration. The findings further indicate that the patterns for men are different, as their fertility increases were less steep and more progressive after migration (Toulemon, 2004). The women in unions experienced stronger and shorter anticipatory effects and greater arrival effects. They quickly adapted their behavior to that of the natives. Among the single women, the disruption effects were found to be quite small, and the arrival effects were found to have occurred later (Devolder and Bueno, 2011). Another work by Alders (2000) focused on cohort effects in fertility within a group of migrants in the Netherlands. He found that older cohorts of Turkish women realized their fertility to a large extent abroad. For example, women born between 1950 and 1954 had 3.5 children on average, half of them born in the Netherlands. Younger cohorts had in total about 2.5 children, but more than four-fifths of them were born in the Netherlands. The age of migration was found to be one possible determining factor for those differences by cohort. Furthermore, the duration of stay was identified as a major variable in migrant fertility (Andersson, 2004).

For Germany, only a small number of studies have been conducted on migrant fertility. One of the reasons for this dearth of research is the lack of suitable data sources. The official population statistics (Bevölkerungsfortschreibung) include information on national and international migration movements. ${ }^{1}$ Foreigners are identified according to their citizenship, which is problematic, as naturalized migrants and ethnic Germans cannot be differentiated from Germans who do not have a migration background. However, the official birth statistics (Geburtenregister) were reformed in 2008. Since then, all births have been registered by the child's biological birth order, the citizenship of the child, and the citizenship of both of the child's parents. Thus, the birth statistics now contain information on the children born in Germany by the origin of the children's parents. But in order to study migrant fertility, it is also necessary to know the exact size of the population at risk. This information is not provided by the population statistics, as they only record the citizenship of individual residents. Thus, these statistics provide insufficient information on the migration backgrounds of the German population.

A second option for studying migrant fertility is to use the German Mikrozensus. The sample size of the Mikrozensus is large enough to allow for the study of specific migrant groups, but detailed fertility analysis using these data was not possible before $2007^{2}$ and no retrospective information on the partnership or employment histories of the respondents is available from the Mikrozensus. A third option is to use social surveys. But because most of these surveys have small sample sizes, they do not allow for distinctions to be made by migrant origin. While there are some studies that have looked specifically at migrant

\footnotetext{
${ }^{1}$ It is based on register data and adjusts the latest census data by adding or subtracting migration flows as well as births and deaths.

${ }^{2}$ Women's total number of births had not been surveyed until the law was amended in 2007.
} 
fertility in Germany, few of them used individual life course data to study migrant fertility behavior from a micro-perspective. Some have taken into account children born abroad (Cygan-Rehm, 2011; Dinkel and Lebok, 1997; Mayer and Riphahn, 1999; Schmid and Kohls, 2009), while others have focused on the fertility behavior of immigrants in Germany (Milewski, 2007, 2010). In the studies by Milewski, a strong interrelation of events was found for migrants from Turkey, Italy, Spain, Greece, and the former Yugoslavia. Thus, migrants experienced elevated birth risks in their first year after immigration, as well as in their first year of marriage. This applies to women who were childless when they migrated, but also to those who already had children before moving. Relative to the first birth risks of the women who moved with their partner, the risks of the women who followed their husband or who moved to form a household were especially high (Milewski, 2007, 2010).

In general, the previous research on Germany could not find any disruption effects shortly after migration for guest worker migrants, independent of birth parity (Mayer and Riphahn, 1999; Milewski, 2007; Schmid and Kohls, 2009). However, ethnic Germans ("Aussiedler") have been shown to experience disruption during the years immediately after they arrive in Germany, with their fertility levels even falling below those of native Germans (Dinkel and Lebok, 1997). While most migrant groups have been found to have high fertility levels when they enter the country (Mayer and Riphahn, 1999; Milewski, 2007, 2010), differences by birth cohort have been detected. For example, in the Turkish case this cohort decline has been shown to correspond to the fertility decline occurring in Turkey (Schmid and Kohls, 2009). Adaptation may also occur over migrant generations. First-generation immigrants have been found to have much higher fertility levels than western German women, while the fertility levels of second-generation immigrants have been shown to lie between those of these two groups (Milewski, 2010). In addition, the age at migration, and thus the number of fertile years spent in the country, has been found to be a determining factor for immigrant fertility (Cygan-Rehm, 2011; Mayer and Riphahn, 1999). Women who arrived after their mid-twenties had higher total fertility than German women (Cygan-Rehm, 2011). The differences in fertility by cohort have also been attributed to the different ages of the cohorts when they migrated, and to differences in their durations of stay (Schmid and Kohls, 2009).

Most of the studies on migrant fertility in Germany have examined several migrant groups combined. In the majority of cases, Turkish migrants were grouped together with other migrants from the former guest worker countries, like Italy, Spain, Greece, and Yugoslavia. This was because the sample sizes were not large enough to allow researchers to conduct statistical analysis by country of origin. However, as migrant groups differ in terms of their migration histories and their cultural and religious backgrounds, we can expect to see differences between migrant groups in terms of their fertility behavior. This study can add to our knowledge of these differences, as it examines the fertility behavior of Turkish migrants only. The study takes a life course perspective. Fertility is thus examined over the whole migration history, and all of the births that 
occurred before and after migration are considered. This allows us to examine the impact of the timing of migration on fertility behavior. Another reason why this study advances our scientific knowledge about migrant behavior in Germany is that, unlike most previous studies, we investigate not just female fertility, but male fertility as well.

\subsection{Working hypotheses}

To examine whether previous findings on migrant fertility behavior in Germany can be confirmed for male and female Turkish migrants, we have formulated working hypothesis based on the above mentioned theories on migrant fertility.

(H1) Disruption: Migration is a stressful event for all international migrants, including for Turkish migrants in Germany. Thus, fertility among Turkish migrants can be expected to be low immediately after the move (H1a). Disruption of fertility may also occur due to temporary separation from the partner. As most of the Turkish migrants in the sample come from families with a guest worker history, it is very likely that the partners did not move together. Typically, a male migrant moved to Germany first, and his wife and children followed later. We can assume that most of the couples were separated in the years preceding the move. Hence, we expect to see a negative anticipation effect on fertility right before migration (H1b).

(H2) Socialization: Fertility levels in Turkey have declined markedly in recent years, but they are still much higher than they are in Germany. ${ }^{3}$ As Turkish migrants are socialized in Turkey, a country with higher fertility norms, they may be expected to have higher fertility levels than the Germans, even after migration (H2a). A second implication of socialization theory is the impact of the age at migration on the fertility level of migrants. If migration occurs during adulthood, the migrant will have been fully socialized in his or her home country, and his or her fertility level will resemble that of the home country. If the migrant moved early in life, a portion of the socialization process will have happened in the country of destination, and the migrant's fertility level may be expected to more closely resemble the native level. The earlier in life a Turkish migrant arrives in Germany, the more likely it is that his or her fertility behavior will resemble German behavior (H2b).

(H3) Adaptation: Turkish migrants are exposed to the economic, political, and cultural conditions in Germany. Thus, contrary to H2a, we expect to find that they adapt their fertility levels to German levels with an increasing duration of stay in the country (H3).

(H4) Interrelation of events: Since our sample mostly consists of Turkish migrants who arrived in Germany after $1973^{4}$, when guest worker recruitment had already stopped and immigration mostly occurred for reasons of family reunion and family formation, we can assume that the majority came for those reasons. Thus, it seems reasonable to expect that we will see the simultaneous

\footnotetext{
${ }^{3}$ See Figure 1 on page 14 for further details.

${ }^{4}$ See also Table 3.
} 
appearance of migration, union formation, and first childbirth among Turkish migrants in Germany. The legitimacy hypothesis may also have some relevance in this context, even though it originally referred to undocumented migration, which does not apply here. For example, parents receive child benefits for children born and raised in Germany. In addition, the time parents spend at home caring for their children is taken into consideration for the calculation of the state pension. This applies to children raised in Germany, whereas for foreigners it depends on the residence permit. If migration is planned well in advance, couples might decide to postpone having a child until the woman arrives in Germany in order to obtain these benefits. Another aspect of German law might be important here for foreigners entering the country for the purposes of family reunion. Until 2005, it could take a migrant to Germany up to four years to receive a work permit, depending on the legal status of the partner. Thus, if migrants came to Germany for the purposes of family reunion or formation, they would not have been allowed to work in the years immediately following their arrival, and fertility during this period would be expected to be high. Thus, not just the concept of the interrelation of events, but also German regulations lead us to expect that birth rates will be elevated shortly after the arrival in Germany (H4a). Hypothesis H4a thus contradicts H1a. As the interrelation of events applies to the first childbirth in particular, we expect to find that first birth risks in particular will be elevated immediately after the move (H4b).

(H5) Selection: The majority of the Turkish migrants in our sample arrived to Germany in the context of family formation or family reunion. Based on those reasons for migration, Turks migrating to Germany form a specific group. In terms of their norms and values, we expect them to be very family-oriented. It also seems reasonable to assume that those migrants who had a partner before they moved to Germany are a select group who can be expected to have had particularly high fertility immediately after the move (H5).

\section{Data and methods}

\subsection{Data}

Our data source is the first wave of the German Generations and Gender Survey (GGS), which was conducted in 2005/06. In addition to the fact that the survey provides detailed birth histories, another advantage of using the German GGS is that it has a sub-sample of Turkish migrants with a size of $n=4000$. The sample was drawn out of all Turkish citizens aged 18 to 79 registered in Germany in 2006. Accordingly, our sample of Turkish respondents was quite selective as well, as it only included migrants who did not acquire German citizenship. The sample was restricted to women and men born between 1950 to 1969, which means that they were aged 36 to 55 at the time of the interview. ${ }^{5}$ Respondents born in Turkey were compared to natives of western Germany, as the guest workers from Turkey migrated to western Germany only. Moreover, the fertility

\footnotetext{
${ }^{5}$ For details, see section 3.2.
} 
patterns in the two parts of Germany still differ markedly. In constructing the sample, we excluded respondents with missing information on the date of birth as well as on the date of migration. In addition, only those cases with nonmissing information on the birth history were retained in the sample. Regarding births, only the biological children of the respondents were taken into account, excluding twins. The sample distribution is shown in Table 10 in the appendix.

\subsection{Methodology}

The methodology follows the approach by Toulemon (2004) (see also Devolder and Bueno, 2011). First of all, age-specific fertility rates are estimated for a first impression on general fertility differences between Turkish migrants and Germans. The estimated rates fluctuate a lot given the small sample size. To focus on the general patterns the curves are smoothed using a three year moving average. Afterwards, total fertility rates are calculated to evaluate the total fertility of the Turkish and German groups. However, TFR measures assume that age groups are homogeneous, which is not the case for migrants as their fertility differs by migration stage. Hence Turkish fertility rates are grouped by age at migration to examine different patterns due to varying life course experiences. For the multivariate analysis discrete-time regression models on the base of the complementary log-log link function are calculated. $P_{i t}$ denotes the probability of having a child in month $t$ for individual $i$. The term $\alpha_{0}$ describes the baseline log-hazard, and $\beta^{\prime}$ represents the estimated regression coefficients for covariates $x$. The simple regression model is expressed by equation (1):

$$
\log \left(-\log \left(1-P_{i t}\right)\right)=\alpha_{0}(t)+\beta^{\prime} x_{i}(t)+\beta^{\prime} x_{i}
$$

Our model contains time-varying as well as time-constant covariates. The main time-varying covariate is the duration of stay, with a range of $-3 \leq x \leq 9$. It contains negative values if the child was born before the parents migrated, and positive values if the childbirth occurred after the migrants' arrival in Germany. ${ }^{6}$ Germans were treated as a reference category. The additional time-varying covariates are the age of the respondent and the union status. ${ }^{7}$ For the models on higher order births, the time to the last birth and the parity are included as well. The time-constant covariates are sex, birth cohort, and the educational status. The latter is based on the ISCED code, and was grouped into the following categories: low education (ISCED code 1-2: primary or lower secondary school degree), intermediate education (ISCED code 3: upper secondary school degree), high education (ISCED code 4-6: post secondary or tertiary degree) and other education (ISCED code 7: still in school or in training, other educational degree, unknown status). ${ }^{8}$

\footnotetext{
${ }^{6}$ The duration of stay is grouped into the following categories: $x<-3,-3 \leq x<-1$, $-1 \leq x<0,0 \leq x<1,1 \leq x<3,3 \leq x<6,6 \leq x<9, x \leq 9$.

${ }^{7}$ In constructing the union and marital status, the missing monthly information was replaced by six, as the union formations and dissolutions were assumed to have happened in the middle of the respective year.

${ }^{8}$ International Standard Classification of Education 1997, http://www.unesco.org/
} 
After we compare the fertility of Turkish migrants to that of Germans, our next step is to examine the determinants for migrant fertility. Discrete-time regression models are calculated for Turkish migrants only, including migrationspecific, time-constant covariates like the first language spoken at home ${ }^{9}$, the age at migration, and the marital status at the time of migration. To gain further insight into migrants' marriage behavior and the relevance for fertility, it would have been helpful to have been able to take into account whether a migrant married during the years immediately after his or her arrival in Germany. Unfortunately, the number of cases in the sample is too small to allow us to do this. Regression models are calculated separately for the transition to a first birth and to higher order births. To avoid outliers, only births that occurred between ages 15 and 45 are considered.

\subsection{Description of the sample}

Unfortunately, the fertility histories of the German GGS were found to be biased for older cohorts (see Kreyenfeld et al., 2010; Sauer et al., 2012). One of the problems with these histories lies in the under-reporting of children no longer living in the household. This might have been due to the sampling method of the German GGS, as well as to the failure to include a question that asked respondents how many children they have in total. As previous studies on the reliability of the birth histories in the German GGS focused on female fertility only, there is no information for male fertility. The German GGS data still appear to be adequate, as the fertility histories for cohorts born after 1950 seem to be usable. As we have chosen to include only respondents who have already experienced most of their fertile life span, the sample consists of men and women of the birth cohorts 1950 to 1969. Table 10 in the appendix displays the number of cases after the construction of our sample, and the restrictions applied to the birth cohort. In total, 3,921 respondents reported having 6,686 children; of these children, 3,148 were first births and 3,538 were higher order births. There are 2,151 women in the sample, of whom 1,554 are of German origin and 597 are of Turkish origin. In addition, 1,770 men are included, of whom 1,190 are German and 580 are Turkish.

In Table 1 the distribution of women and men in our sample by birth cohort and educational status is shown. Among the Turkish group, men are more likely to belong to the younger birth cohorts than women. Among the Germans, the birth cohorts are more equally distributed and the differences between the men and women are smaller. In our sample, the German women are a bit older than the German men, which largely reflects the gender distribution in the German population. There are huge differences between the Turkish and the German

education/information/nfsunesco/doc/isced_1997.htm. Unfortunately, no time-varying information on education is available. The variable on education therefore refers to the highest school degree obtained, which can be assumed to be constant over the life course.

${ }^{9}$ This covariate refers to the language use at the time of the interview. Nevertheless, it can be used under the assumption that language use at home did not change over the studied period. 
Table 1: Sample distribution by cohort and educational status. German and Turkish respondents by sex. Column percent.

\begin{tabular}{|c|c|c|c|c|c|c|}
\hline Turkish & $\begin{array}{r}\text { Male } \\
\text { Absolute }\end{array}$ & $\begin{array}{l}\text { Column } \\
\text { percent }\end{array}$ & $\begin{array}{r}\text { Female } \\
\text { Absolute }\end{array}$ & $\begin{array}{l}\text { Column } \\
\text { percent }\end{array}$ & $\begin{array}{r}\text { Total } \\
\text { Absolute }\end{array}$ & $\begin{array}{l}\text { Column } \\
\text { percent }\end{array}$ \\
\hline \multicolumn{7}{|l|}{ Cohort } \\
\hline $1950-1954$ & 58 & 10.00 & 114 & 19.10 & 172 & 14.61 \\
\hline 1955-1959 & 107 & 18.45 & 110 & 18.43 & 217 & 18.44 \\
\hline $1960-1964$ & 189 & 32.59 & 158 & 26.47 & 347 & 29.48 \\
\hline 1965-1969 & 226 & 38.97 & 215 & 36.01 & 441 & 37.47 \\
\hline \multicolumn{7}{|l|}{ Education } \\
\hline Low & 281 & 48.45 & 443 & 74.20 & 724 & 61.51 \\
\hline Middle & 194 & 33.45 & 83 & 13.90 & 277 & 23.53 \\
\hline High & 62 & 10.69 & 21 & 3.52 & 83 & 7.05 \\
\hline Other & 43 & 7.41 & 50 & 8.38 & 93 & 7.90 \\
\hline Total & 580 & 100 & 597 & 100 & 1177 & 100 \\
\hline \multirow[t]{2}{*}{ German } & Male & & Female & & Total & \\
\hline & Absolute & $\begin{array}{l}\text { Column } \\
\text { percent }\end{array}$ & Absolute & $\begin{array}{c}\text { Column } \\
\text { percent }\end{array}$ & Absolute & $\begin{array}{l}\text { Column } \\
\text { percent }\end{array}$ \\
\hline \multicolumn{7}{|l|}{ Cohort } \\
\hline $1950-1954$ & 265 & 22.27 & 297 & 19.11 & 562 & 20.48 \\
\hline $1955-1959$ & 283 & 23.78 & 383 & 24.65 & 666 & 24.27 \\
\hline $1960-1964$ & 342 & 28.74 & 438 & 28.19 & 780 & 28.43 \\
\hline 1965-1969 & 300 & 25.21 & 436 & 28.06 & 736 & 26.82 \\
\hline Education & & & & & 0 & \\
\hline Low & 59 & 4.96 & 145 & 9.33 & 204 & 7.43 \\
\hline Middle & 613 & 51.51 & 858 & 55.21 & 1471 & 53.61 \\
\hline High & 504 & 42.35 & 530 & 34.11 & 1034 & 37.68 \\
\hline Other & 14 & 1.18 & 21 & 1.35 & 35 & 1.28 \\
\hline Total & 1190 & 100 & 1554 & 100 & 2744 & 100 \\
\hline
\end{tabular}

Notes: German GGS 2005/06, unweighted (own calculations).

respondents in terms of educational status. Among the German women, only around nine percent has a low educational status; i.e., a primary or a lower secondary school degree only. The opposite is the case for the Turkish women, 74 percent of whom have no education beyond the primary or lower secondary level. One-third of the German women reported having a post-secondary school degree or higher, compared to 3.5 percent of the Turkish women. The same patterns have been observed among the men, but the differences between the Turkish and the German men are smaller than those between the women.

The migration-specific variables are shown in Tables 2 and 3 . All of the Turkish respondents in the sample belong to the first generation of migrants. The majority entered the country at young ages. Only 24 percent of the men and 23 percent of the women migrated after age 25 . Most of the male migrants 
Table 2: Distribution of Turkish sample by age at migration and birth cohort. Column percent.

\begin{tabular}{crrrr}
\hline & \multicolumn{4}{c}{ Birth cohort } \\
Age at migration & $1950-54$ & $1955-59$ & $1960-64$ & $1965-69$ \\
\hline $0-9$ & 1.74 & 6.02 & 13.87 & 21.73 \\
$10-14$ & 1.74 & 20.83 & 20.23 & 22.20 \\
$15-19$ & 25.00 & 26.39 & 28.61 & 13.32 \\
$20-24$ & 43.02 & 25.00 & 8.96 & 22.90 \\
$25-29$ & 13.37 & 7.41 & 11.85 & 11.68 \\
$30-50$ & 15.12 & 14.35 & 16.47 & 8.18 \\
\hline Total & 100 & 100 & 100 & 100 \\
\hline \hline \multicolumn{4}{c}{$\chi^{2}=239.0607, \mathrm{df}=21$, p-value $<2.2 \mathrm{e}-16$} \\
Notes: German GGS 2005/06, unweighted (own calculations).
\end{tabular}

arrived between the ages of 10 and 19, and most of the female migrants came to Germany between the ages of 15 and 24. As quite a large share of the Turkish migrants in the sample migrated before age 15 , we need to consider the possibility that they did not move on their own, and that they came to Germany as dependent movers. This share is higher among the men than among the women. In addition, the $\chi^{2}$-test shows that the birth cohort and the age at migration are correlated for our sample. While the majority of migrants from older birth cohorts migrated at adult ages, the migrants who were born between 1960 and 1969 mostly arrived during infancy. We should be aware of that correlation when interpreting the multivariate results. Some additional hints regarding the composition of our sample are provided by the year of immigration: 21 percent of the Turkish men and about 19 percent of the women arrived in Germany before 1973, the year when the recruitment agreement between Turkey and Germany was terminated. As immigration after 1973 was only possible for the purposes of family reunification or family formation, we assume that the majority of the Turkish immigrants in our sample came to Germany for those reasons. Next, we observe that 54 percent of the Turkish men and 39 percent of the Turkish women were married before they migrated to Germany. Unfortunately, the sample size was too small to allow us to make more detailed distinctions by marital status. 
Table 3: Sample distribution by migration-specific variables. Turkish respondents by sex. Column percent.

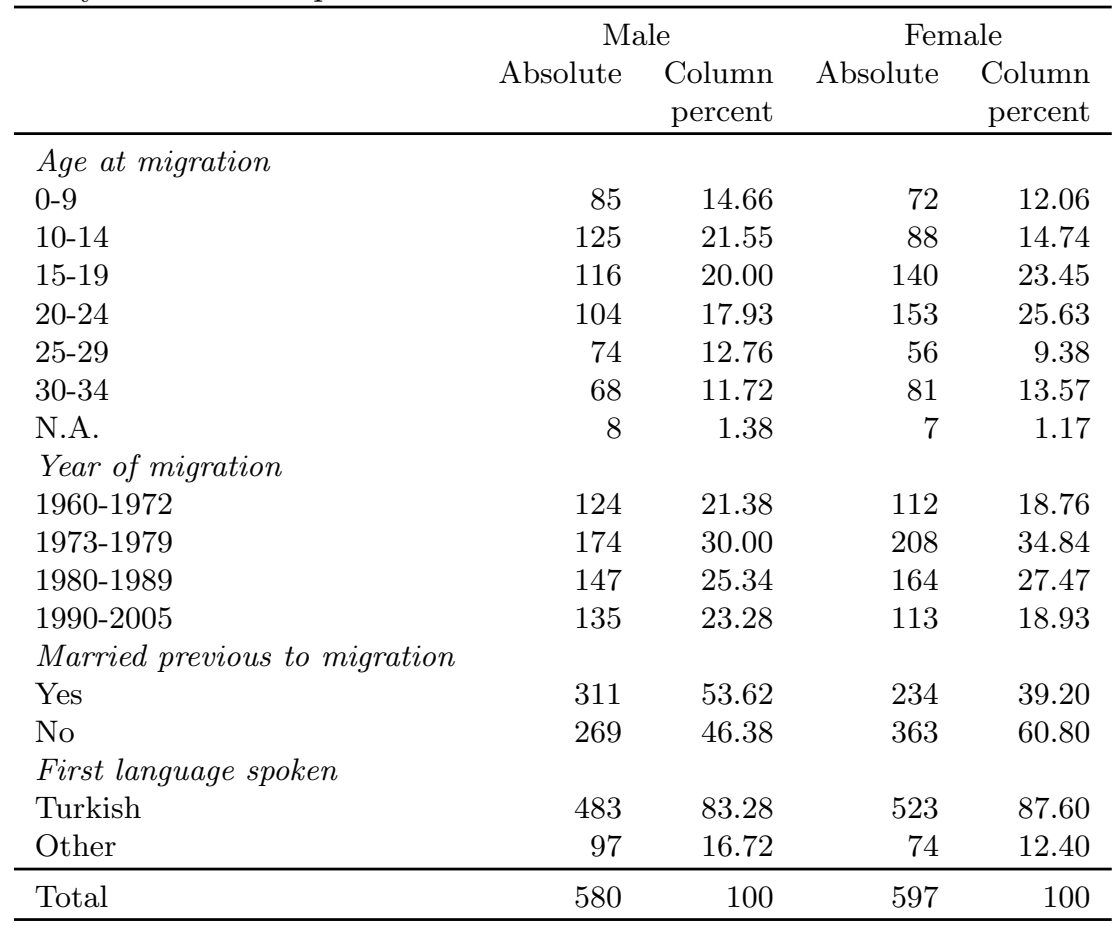

Notes: German GGS 2005/06, unweighted (own calculations).

\section{Results}

\subsection{Descriptives}

Figure 1 illustrates the development of total fertility rates for both Turkey and Germany ${ }^{10}$ over the last decades. For additional insight into possible tempo effects the mean age at childbirth (MAC) is shown. ${ }^{11}$ We can see that German fertility development has been characterized by a relatively stable TFR, which has remained around replacement level since the 1970s. In Turkey, by contrast, there has been a steep fertility decline. The TFR fell from around 6.6 in the 1950 s to 2.2 in the period 2005 to 2010 . Yet even after this sharp decrease, the Turkish TFR is still much higher than the German TFR. The Turkish women not only continue to have more children; they also give birth earlier in their life course (see Table 4 for the MAC in Turkey and Germany). In the period 1990 to 2010, the Turkish MAC was above that of Germany. But while the MAC

\footnotetext{
${ }^{10}$ The total fertility for eastern and western Germany combined is displayed.

${ }^{11}$ Unfortunately, the mean age at first childbirth is not available for Germany before 2009. Thus, the mean age at childbirth for all parities is used. The TFR and the MAC are given as five-year averages; e.g., the value for 1950 corresponds to the period 1950-1955.
} 
was rising in Germany, it remained more constant in Turkey. Thus, the gap between the two values has increased. The fertility patterns in Turkey are also characterized by considerable differences between rural and urban regions. For example, in 2003 the TFR of women living in urban environments was about 1.68, whereas the TFR of women living in rural areas was, at 3.63, more than twice as high (Eryurt and Koç, 2012). In sum, as there has been a sharp decline in fertility in Turkey, the birth cohort of the Turkish migrants cannot be neglected. Ideally, information on the degree of urbanization in the migrants' region of origin would be taken into account as well. Unfortunately, however, the GGS provides no information on the region of origin of migrants.

Figure 1: Total fertility rate in Turkey and Germany, 1950-2005.

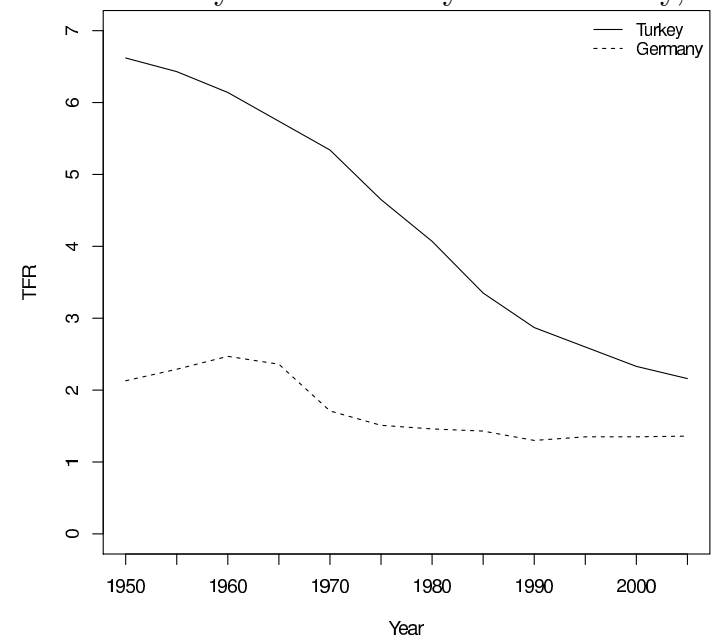

United Nations Population Division (2012).

Table 4: Mean age at childbirth in Turkey and Germany.

\begin{tabular}{cccc}
\hline & MAC Germany & MAC Turkey & $\Delta$ \\
\hline $1990-1995$ & 27.95 & 26.70 & 1.25 \\
$1995-2000$ & 28.52 & 26.94 & 1.58 \\
$2000-2005$ & 29.06 & 27.18 & 1.88 \\
$2005-2010$ & 29.91 & 27.42 & 2.49 \\
\hline
\end{tabular}

United Nations Population Division (2012).

Figure 2 illustrates the smoothed age-specific fertility rates for the Turkish and the German women and men. The calculations are based on the number of children born to the respondents aged 15 to 45 . The resulting TFR refers to the period from 1966 to 2006. Overall, the fertility level of the Turkish respondents 
Figure 2: Age-specific fertility rates by origin and sex.
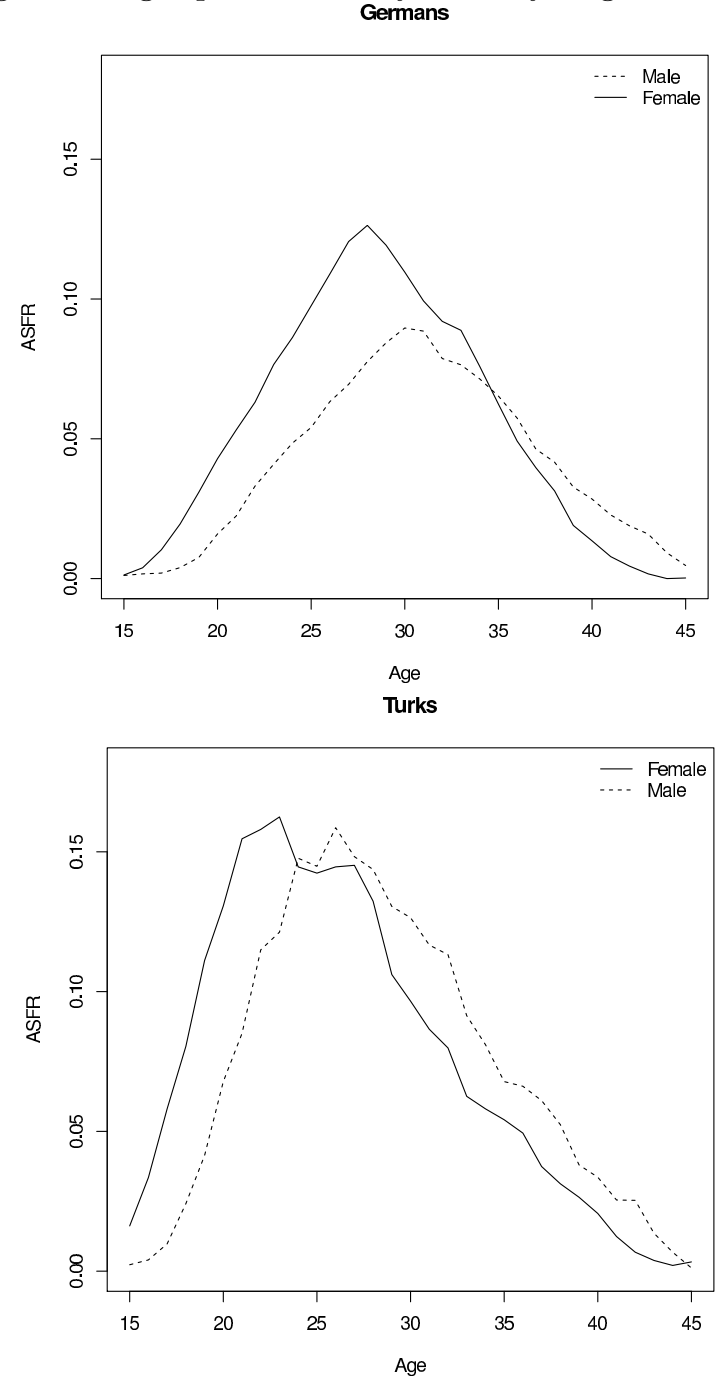

Notes: German GGS 2005/06, unweighted (own calculations). 
is higher than that of the German respondents. Childbirth also occurs earlier in life among the Turkish migrants than among the Germans: the mean age at first childbirth is much lower for the Turkish women and men (see Table 5). Among both the Turkish migrants and the Germans, women have their first child at younger ages than the men: for the German women we can see a bell-shaped curve with a peak around 28; while for the Turkish women the agespecific fertility rates show a second bump around age 27 . This could be a result of heterogeneity within the migrant group, probably by age at migration.

Figure 3: Age-specific fertility rates by age at migration and gender.

\section{Women}

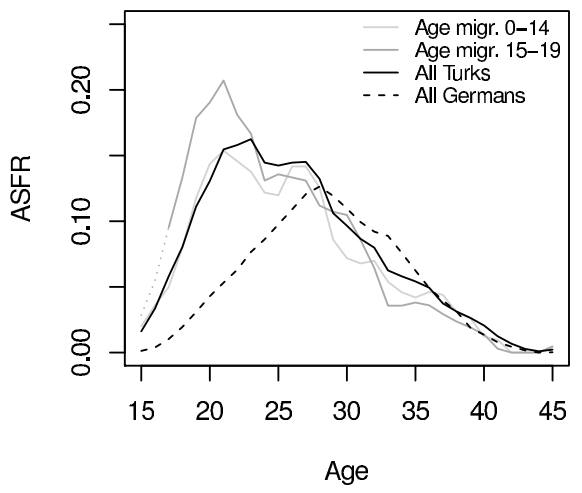

Women

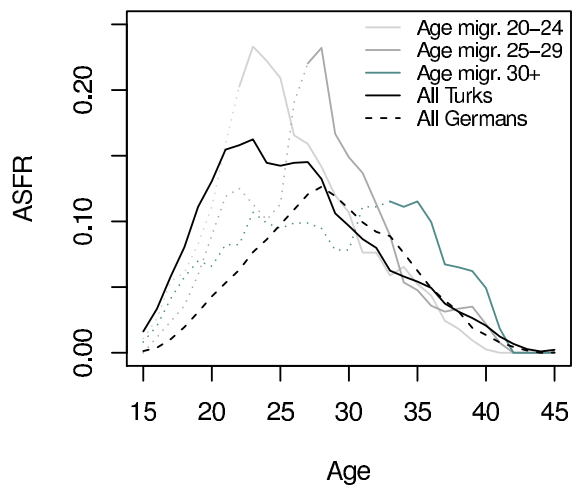

Men

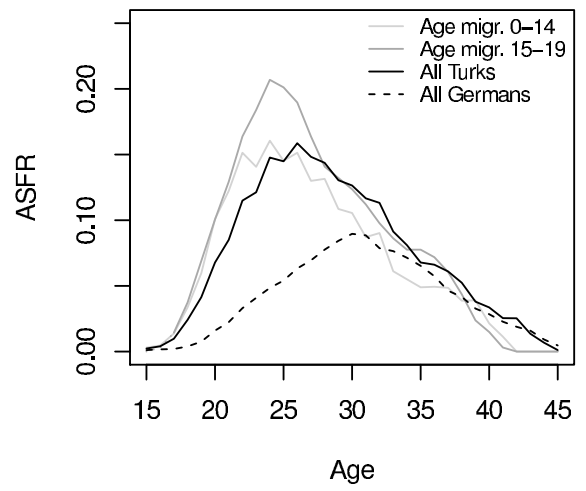

Men

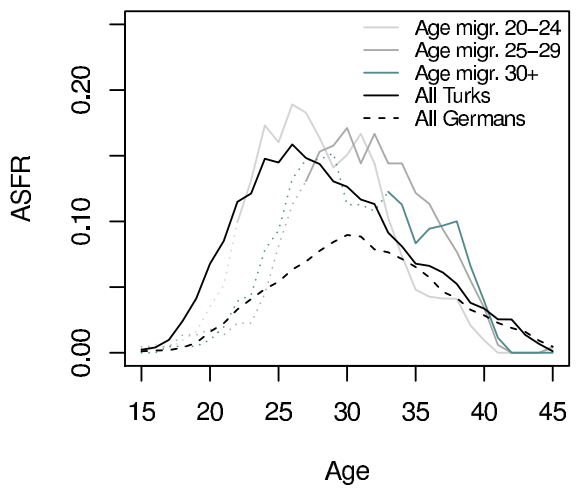

Notes: German GGS 2005/06, unweighted (own calculations).

In Figure 3 the age-specific fertility rates for women and men are displayed by age at migration. The curves are dotted while the migrants still lived in Turkey, and become solid lines after migration. ${ }^{12}$ This indicates that the age

${ }^{12}$ This holds under the assumption that Turkish men and women migrated directly from 
at migration influences fertility rates in the short term. The Turkish migrants who arrived before age 15 have fertility rates similar to the overall values among Turkish migrants. The women who migrated between the ages of 15 and 29 not only have higher fertility in general, but have elevated rates in the years directly following migration. This trend appears to be present to a much smaller extent among men. In addition, the effect for the men seems to be slightly postponed. The fertility rates of migrants arriving after age 30 most closely resemble the German rates. This finding is confirmed by the total fertility rates grouped by age at migration (see Table 5). The migrants who arrived in Germany before age 15 or after age 30 show significantly lower TFRs than those who arrived during young adulthood. For the Turkish men, the $M A C_{1}$ seems to have increased along with the age at migration. For the Turkish women, the $M A C_{1}$ is additionally elevated for those who moved to Germany before age 19. It appears that the age of migration has a significant effect on the fertility of the Turkish migrants in Germany. We can therefore see that this heterogeneous group of Turks need to be analyzed separately by their different ages at migration.

Table 5: Total fertility rate and mean age at first childbirth by age at migration.

\begin{tabular}{lcccc}
\hline & TFR & \multicolumn{3}{c}{$M A C_{1}$} \\
Age at migration & Male & Female & Male & Female \\
\hline $0-14$ & 2.08 & 2.15 & 24.4 & 25.20 \\
$15-19$ & 2.61 & 2.49 & 24.3 & 26.00 \\
$20-24$ & 2.29 & 2.49 & 26.2 & 23.00 \\
$25-29$ & 2.19 & 2.44 & 28.4 & 24.20 \\
$30-50$ & 2.04 & 2.18 & 28.9 & 28.90 \\
\hline All Turks & 2.28 & 2.35 & 25.7 & 24.9 \\
All Germans & 1.27 & 1.67 & 29.7 & 26.6 \\
\hline
\end{tabular}

Notes: German GGS 2005/06, unweighted (own calculations).

Another factor that might influence age-specific fertility rates is the marriage behavior of migrants. One way to examine the possible interrelations between several life course events graphically is to use event plots (Figure 11 and Figure 12 in the appendix). In Figure 11 we can see that the birth of the first child often occurs shortly after migration, especially for those migrants who arrived between the ages of 20 and 30. In Figure 12 the group of migrants was split into those who were already married before migration and those who were not. The close occurrence of the first birth and migration again becomes apparent for those migrants who were married before migration. But for the other group of migrants who were not married at migration, the birth of the first child seems

Turkey to Germany. Only if this was the case we can view the dotted part of the age-specific fertility rates as fertility that took place in the home country, and the solid lines marking fertility in the host country. As a threshold value for the distinction between fertility before and after migration, the mean age at migration within these groups was used. For migrants arriving after age 30 , the value was set to 33 . 
to occur much later. These graphic presentations are not, of course, substitutes for statistical analysis, but they do allow us to gain some insight into the visible correlations. This can be particularly useful when the sample sizes are small, and the estimation of regression models is therefore limited.

\subsection{Multivariate analysis}

\subsubsection{Turkish migrant fertility in comparison to German fertility}

Since the migrants who arrived during childhood were not yet in their reproductive phase, they were not at risk of changing their behavior in response to migration. For that reason, the Turkish sample is restricted to the women and men who arrived after their 20th birthday in all the following models. The results of the regression models are shown in two different ways. First, the corresponding regression model is displayed in Table 6 . The impact of the duration of stay on the risk of having a first birth is displayed graphically in Figure 4 .

Table 6 shows that not only the duration of stay, but also the person's age, sex, and union status determine the transition to the first birth. Among the women, the risk of having a first birth is about 20 percent higher than it is among the men. In addition, fertility is positively influenced if the respondents are in a union. ${ }^{13}$ Surprisingly, no significant differences in fertility risks can be found between the educational groups, or between the more recent cohorts and the cohorts born between 1954 and 1959 .

Figure 4 shows the risks of having a first child by duration of stay for the male and the female respondents combined. The vertical markers illustrate the 90 percent confidence intervals. The horizontal line refers to the relative fertility risks of all of the Germans combined. It turns out that the duration of stay has a considerable impact on the fertility of the Turkish migrants. In the years preceding migration, the risk of having a child is a little lower than it was for the Germans. But in the years immediately after migration, the risk increases and is about 3.5 times higher than it is among the Germans. In the subsequent years, it decreases and falls below the German level about seven years after migration.

\footnotetext{
${ }^{13}$ The category "union status missing" is included in the regression models as there are several missing values for the time-varying union status.
} 
Table 6: Complementary log-log model. Relative risks of having a first birth. Turkish and German respondents.

\begin{tabular}{|c|c|}
\hline & Model 1 \\
\hline Intercept & $0.0003^{* * *}$ \\
\hline Germans & 1 \\
\hline Duration of stay -3 & 1.18 \\
\hline Duration of stay -2 & 0.75 \\
\hline Duration of stay -1 & 0.92 \\
\hline Duration of stay 0 & $3.59^{* * *}$ \\
\hline Duration of stay 1-2 & $2.38 * * *$ \\
\hline Duration of stay $3-5$ & 1.03 \\
\hline Duration of stay $6-8$ & $0.69^{*}$ \\
\hline Duration of stay $9+$ & $0.40^{* * *}$ \\
\hline Age $15-19$ & 1 \\
\hline Age $20-24$ & $4.12^{* * *}$ \\
\hline Age $25-29$ & $5.27 * * *$ \\
\hline Age $30-34$ & $3.85^{* * *}$ \\
\hline Age $35+$ & $1.24^{*}$ \\
\hline Male & 1 \\
\hline Female & $1.20 * * *$ \\
\hline Cohort 1950-54 & 0.95 \\
\hline Cohort 1954-59 & 1 \\
\hline Cohort 1960-64 & 1.00 \\
\hline Cohort 1965-69 & 1.04 \\
\hline Education low & 1 \\
\hline Education medium & 1.03 \\
\hline Education high & 1.01 \\
\hline Education other & 0.96 \\
\hline Not in union & 1 \\
\hline In union & $2.37 * * *$ \\
\hline Union status missing & $1.93^{* * *}$ \\
\hline Log Likelihood & -17402.81 \\
\hline Number of events & 2571 \\
\hline Person months & 1089957 \\
\hline
\end{tabular}

*** $p<0.001,{ }^{* *} p<0.01,{ }^{*} p<0.05$

Notes: German GGS 2005/06 (own calculations). 
Figure 4: Relative risk of having a first birth by duration of stay. Turkish and German respondents. Both sexes combined.

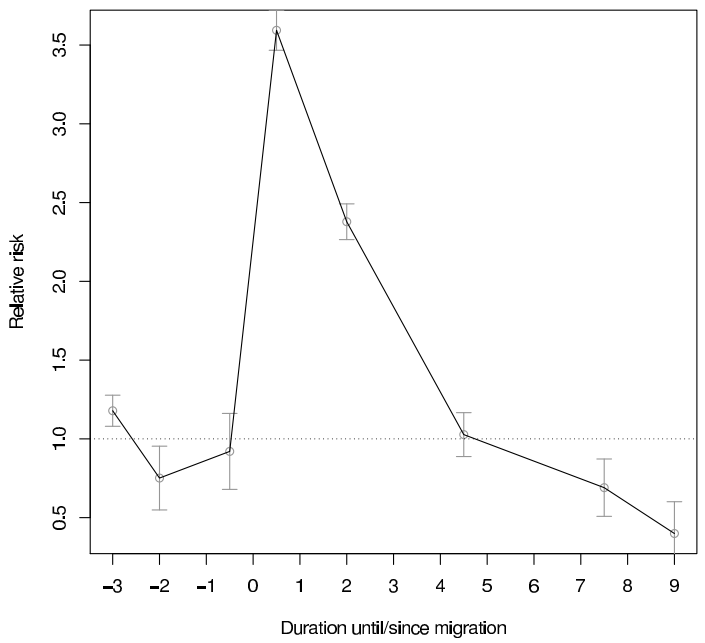

Notes: Controlled for age, sex, cohort, education and union status. The horizontal line at $y=1$ refers to the relative risk for all Germans combined.

German GGS 2005/06 (own calculations).

The next Figure 5 displays the interaction between the duration of stay and the respondents' sex (the corresponding values can be seen in Table 11 in the appendix). It reveals that the duration of stay operates differently for the women than it does for the men. A disruption of fertility in the years following migration is not found for either the women or the men. Both sexes have elevated fertility risks during those years, but the arrival effect is more distinct for the women. There are some signs of a negative anticipation effect preceding the move, particularly among the women. The fact that the effect is so small might, however, be attributable to the very low (relative to other countries) fertility levels of our reference group of western Germans. Thus, we cannot rule out the existence of a negative anticipation effect on Turkish migrant fertility. Instead of finding that the Turkish migrants have a consistently higher fertility level than the Germans, as the socialization hypothesis implies, we find the fertility risk decreased the longer the migrants stay in the country. The Turkish fertility risks even fall below the German levels around three to six years after migration for the women and more than nine years after migration for the men. This development is probably a result of the very high fertility risks in the years immediately after migration. Thus, it is hard to separate out an adaptation effect.

Table 7 and Figure 6 display the corresponding results for the model on higher order birth transitions. The regression Table 7 shows that being in a union as well as having a high educational level increases the risk of having a 
higher order birth. We also find cohort effects. The later a respondent was born, the higher his or her risk of having a higher order birth. As these results seem implausible, Table 13 in the appendix shows additional regression results separately by origin and sex. ${ }^{14}$ As the focus of this work is on Turkish migrants and their fertility by migration timing, the biased finding for the German women on cohort fertility are not relevant here. Finally, the table reveals that for higher order births the risks do not differ significantly by sex, and that none of the older age groups differs from the youngest group aged 15-19.

Figure 5: Interaction between duration of stay and sex. Relative risks of having a first birth. Turkish and German respondents.

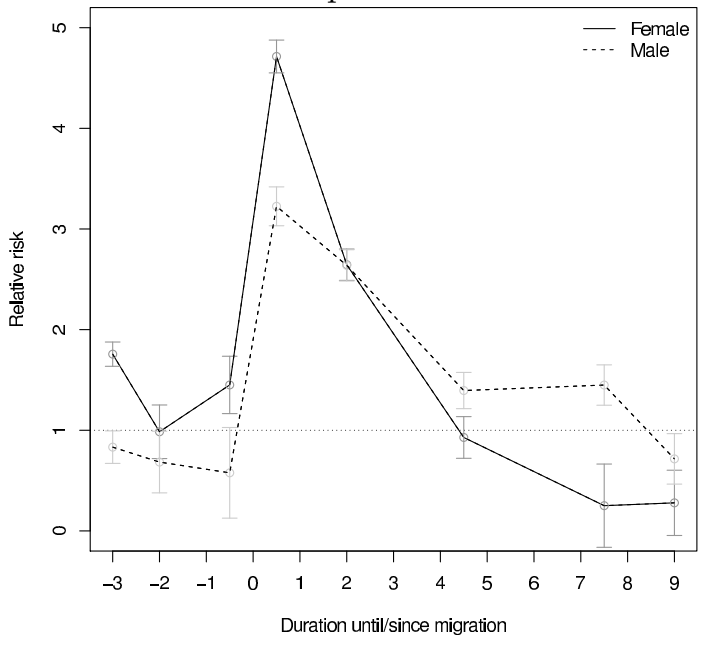

Notes: Controlled for age, cohort, education and union status. The horizontal line at $y=1$ refers to the relative risk for all Germans combined. German GGS 2005/06 (own calculations).

The fertility risks by duration of stay are displayed in Figure 6 . In general, the risk of having a second or higher order child is higher for the Turkish migrants than it is for the Germans. Like for the transition to the first birth, no disruption of fertility occurs shortly after arrival. The opposite is found to be the case: the risks are elevated during the years immediately following migration. Therefore, the hypothesis regarding the interrelation of events could be verified for both the transition to the first birth and to higher order births. In the following years, fertility risks decrease but rise again slightly around six to eight years after migration. Although the risks fall about nine years after

\footnotetext{
${ }^{14}$ It turns out that the cohort effects occur mainly among the German women in the sample. This is probably due to the sampling problems in the GGS (see also page 10). The same is true for our results on birth parity. In the regression model (Table 7) it appears that the rates of third and fourth births are quite high. Table 13 shows that this problem also arises from the results for the German women.
} 
Figure 6: Relative risk of having a higher order birth by duration of stay. Turkish and German respondents. Both sexes combined.

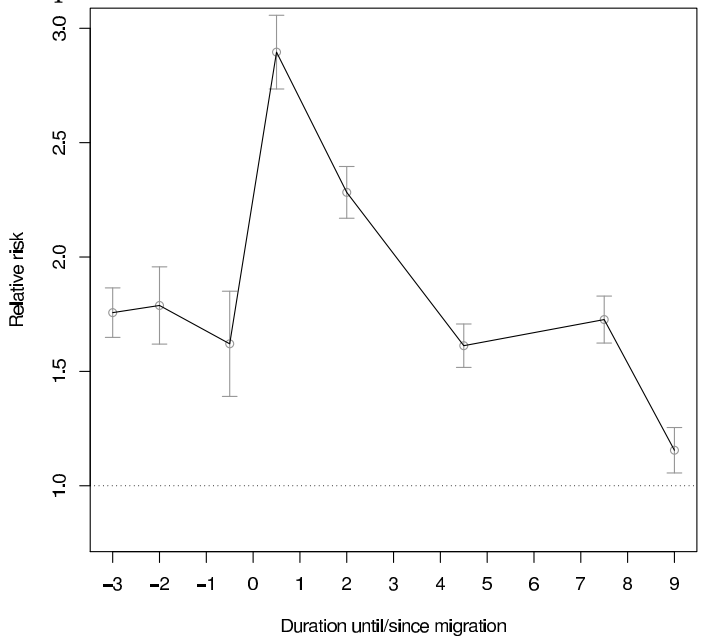

Notes: Controlled for time distance to last birth, parity, age, sex, cohort, education and union status. The horizontal line at $y=1$ refers to the relative risk for all Germans combined. German GGS 2005/06 (own calculations).

migration, it is hard to say whether this effect is attributable to adaptation. In general, the migrants' fertility risks remain consistently higher than those of the Germans until about nine years after migration. Hence, the socialization theory is confirmed for the transition to higher order births. Again, the anticipation effect of lower fertility risks preceding the move is very small.

An interaction between the duration of stay and sex was also found, as can be seen in Figure 7 (see the corresponding values in Table 12 in the appendix). For higher order births, no disruption of fertility occurs among the male Turkish migrants, but the fertility risks decrease slightly among the female migrants in the years preceding the move. Compared to German levels, fertility is particularly high for the female migrants immediately after their arrival in Germany; but no positive arrival effect was found for the male migrants. 
Table 7: Complementary log-log model. Relative risks of having a higher order birth. Turkish and German respondents.

\begin{tabular}{|c|c|}
\hline & Model 2 \\
\hline Intercept & $0.0023^{* * *}$ \\
\hline Germans & 1 \\
\hline Duration of stay -3 & $1.76^{* * *}$ \\
\hline Duration of stay -2 & $1.79 * * *$ \\
\hline Duration of stay -1 & $1.62 *$ \\
\hline Duration of stay 0 & $2.90 * * *$ \\
\hline Duration of stay $1-2$ & $2.28^{* * *}$ \\
\hline Duration of stay $3-5$ & $1.61^{* * *}$ \\
\hline Duration of stay $6-8$ & $1.73^{* * *}$ \\
\hline Duration of stay $9+$ & 1.16 \\
\hline Time distance to last birth 1 year & 1 \\
\hline Time distance to last birth 2 years & $3.10^{* * *}$ \\
\hline Time distance to last birth $3-4$ years & $2.61^{* * *}$ \\
\hline Time distance to last birth $5+$ years & $1.17^{* *}$ \\
\hline Parity 1 & 1 \\
\hline Parity 2 & $0.42^{* * *}$ \\
\hline Parity 3 & $0.47 * * *$ \\
\hline Parity $4+$ & $0.70^{* *}$ \\
\hline Age $15-19$ & 1 \\
\hline Age $20-24$ & 1.42 \\
\hline Age $25-29$ & 1.56 \\
\hline Age $30-34$ & 1.41 \\
\hline Age $35+$ & 0.74 \\
\hline Male & 1 \\
\hline Female & 0.99 \\
\hline Cohort 1950-54 & $0.86^{*}$ \\
\hline Cohort 1955-59 & 1 \\
\hline Cohort 1960-64 & $1.21^{* * *}$ \\
\hline Cohort 1965-69 & $1.24^{* * *}$ \\
\hline Education low & 1 \\
\hline Education medium & 0.89 \\
\hline Education high & $1.26^{* * *}$ \\
\hline Education other & 0.96 \\
\hline Not in union & 1 \\
\hline In union & $1.59 * * *$ \\
\hline Union status missing & $1.60^{* * *}$ \\
\hline Log Likelihood & -15373.67 \\
\hline Number of events & 2648 \\
\hline Person months & 466148 \\
\hline
\end{tabular}

${ }^{* * *} p<0.001,{ }^{* *} p<0.01,{ }^{*} p<0.05$

Notes: German GGS 2005/06 (own calculations). 
Figure 7: Interaction between duration of stay and sex. Relative risks of having a higher order birth.

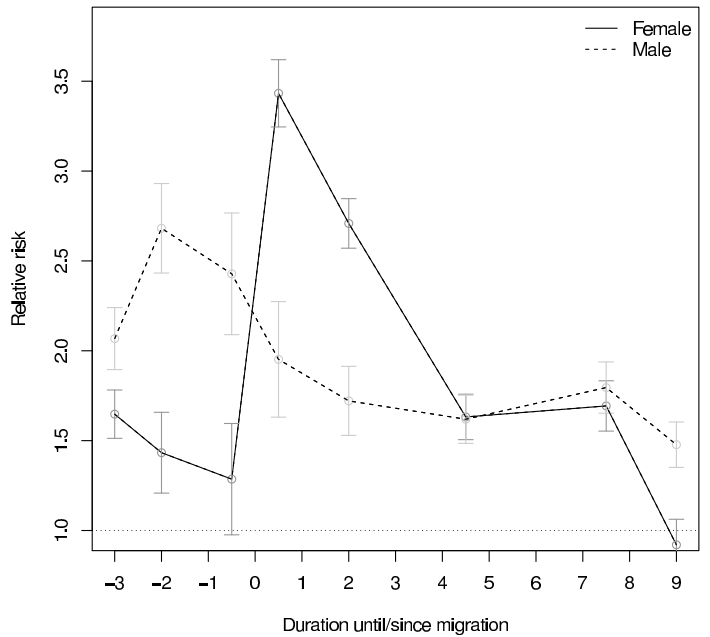

Notes: Controlled for time distance to last birth, parity, age, sex, cohort, education and union status. The horizontal line at $y=1$ refers to the relative risk for all Germans combined. German GGS 2005/06 (own calculations).

\subsubsection{Determinants of Turkish migrant fertility}

The next regression models are calculated for the Turkish migrants only in order to add migration-specific covariates. As the duration of stay, the age of the respondent, and the age at migration are closely related to each other, they could not be included in a single model at the same time. The models presented are based on the age at migration and the duration of stay, but the corresponding regression results that include the age of the respondent are provided in the appendix. Table 8 contains the results of a regression model on the transition to the first birth based on the duration and the age at migration. In sum, the Turkish men and women do not differ in their risk of having a first child.

Indeed, none of the explanatory variables were found to have a significant impact on the fertility risk apart from the age at migration and the duration of stay. The older the migrants are at migration, the lower their risk of having a first child. For those who migrated at age 30 or older, the risk is about 37 percent lower than it is for those migrating between the ages of 20 and 24. This finding contradicts our socialization hypothesis. We expected to find that the Turkish migrants who migrated earlier in life have lower fertility levels. The positive effect of being married prior to migration on fertility immediately following migration is not confirmed for the transition to the first birth. However, being married before migration does influence fertility risks. A similar model that takes into account the age of the respondents instead of the age at migration is 
Table 8: Complementary log-log model. Relative risks of having a first birth. Turkish respondents only.

\begin{tabular}{ll}
\hline & Model 3a \\
\hline Intercept & $0.0097^{* * *}$ \\
Duration of stay -3 & $0.23^{* * *}$ \\
Duration of stay -2 & $0.17^{* * *}$ \\
Duration of stay -1 & $0.24^{* * *}$ \\
Duration of stay 0 & 1 \\
Duration of stay 1-2 & $0.66^{* *}$ \\
Duration of stay 3-5 & $0.28^{* * *}$ \\
Duration of stay 6-8 & $0.16^{* * *}$ \\
Duration of stay 9+ & $0.04^{* * *}$ \\
Age at migration 20-24 & 1 \\
Age at migration 25-29 & 0.82 \\
Age at migration 30+ & $0.63^{* * *}$ \\
Male & 1 \\
Female & 1.08 \\
Cohort 1950-54 & 0.88 \\
Cohort 1955-59 & 1 \\
Cohort 1960-64 & 0.99 \\
Cohort 1965-69 & 1.02 \\
Education low & 1 \\
Education medium & 1.10 \\
Education high & 0.94 \\
Education other & 1.08 \\
Not married before migration & 1 \\
Married before migration & 1.17 \\
First language German/other & 1 \\
First language Turkish & 1.04 \\
\hline Log Likelihood & -3126.12 \\
Number of events & 475 \\
Person months & 178884 \\
\hline
\end{tabular}

${ }^{* * *} p<0.001,{ }^{* *} p<0.01,{ }^{*} p<0.05$

Notes: German GGS 2005/06 (own calculations).

shown in Table 14 in the appendix. The risk of having a first birth is highest for the Turkish migrants between the ages of 20 and 29. All of the other covariates show results similar to those in the previous model.

The impact of the duration of stay is illustrated in Figure 8. For all of the following figures, the reference category changed. The horizontal line now marks the relative risk among the Turkish migrants of having a child in the year of migration. It turns out that the risk in the year of migration is higher than in the periods before or after migration. Six to eight years after migration, the risk is 80 percent lower than it was in the year of migration. In the years preceding migration, the risk of having a first child is at a similarly low level.

Table 9 and Figure 9 show the results for the transition to higher order births. In general, the impact of the duration of stay seems to be smaller than it is in the models for the first birth. The age at migration negatively influences the 
Figure 8: Relative risks of having a first birth by duration of stay. Turkish respondents only. Both sexes combined.

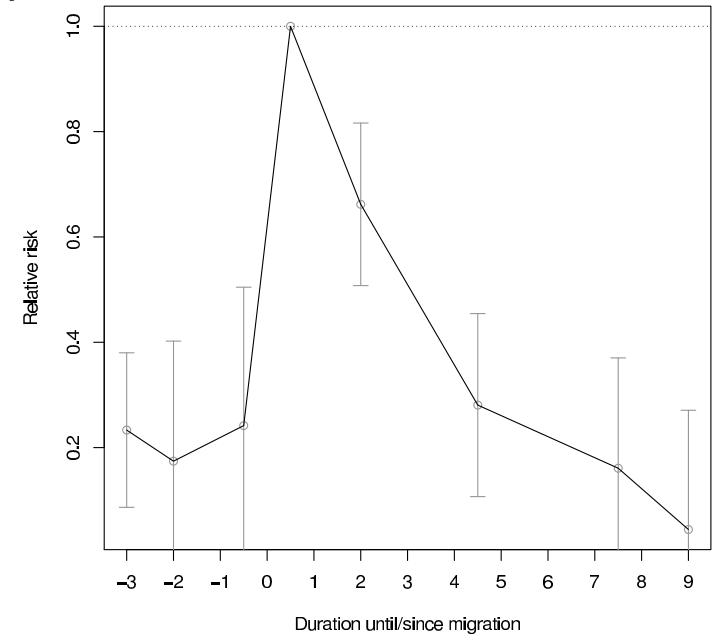

Notes: Controlled for age at migration, sex, cohort, education, marital status and language use. The horizontal line at $y=1$ refers to the relative risk for Turks in the year of migration. German GGS 2005/06 (own calculations).

risk of fertility: i.e., the higher the age at migration, the lower the risk of having a higher order child. Again, our socialization hypothesis, which anticipates a positive relationship between the age at migration and fertility, must be rejected. We also find surprising sex differences. The fertility risks of the women are smaller than those of the men, but we have no intuitive explanation of why this is the case. In addition, the marital status influences the risk of having a higher order birth. A migrant's fertility risk increases 34 percent if he or she was married before migration. Unfortunately, the number of events is too small to allow us to estimate an interaction between our marriage covariate and the duration of stay. 
Table 9: Complementary log-log model. Relative risks of having a higher order birth. Turkish respondents only.

\begin{tabular}{|c|c|}
\hline & Model $4 \mathrm{a}$ \\
\hline Intercept & $0.0176^{* * *}$ \\
\hline Duration of stay -3 & 0.77 \\
\hline Duration of stay -2 & 0.65 \\
\hline Duration of stay -1 & $0.57^{*}$ \\
\hline Duration of stay 0 & 1 \\
\hline Duration of stay $1-2$ & 0.76 \\
\hline Duration of stay $3-5$ & $0.56^{* * *}$ \\
\hline Duration of stay $6-8$ & $0.46 * * *$ \\
\hline Duration of stay $9+$ & $0.18^{* * *}$ \\
\hline Time distance to last birth 1 year & 1 \\
\hline Time distance to last birth 2 years & $2.13^{* * *}$ \\
\hline Time distance to last birth $3-4$ years & $2.00 * * *$ \\
\hline Time distance to last birth $5+$ years & $1.36^{* *}$ \\
\hline Parity 1 & 1 \\
\hline Parity 2 & $0.63^{* * *}$ \\
\hline Parity 3 & $0.48^{* * *}$ \\
\hline Parity $4+$ & $0.68^{* *}$ \\
\hline Age at migration 20-24 & 1 \\
\hline Age at migration $25-29$ & $0.81^{*}$ \\
\hline Age at migration $30+$ & $0.60^{* * *}$ \\
\hline Male & 1 \\
\hline Female & $0.81^{*}$ \\
\hline Cohort 1950-54 & 0.81 \\
\hline Cohort 1954-59 & 1 \\
\hline Cohort 1960-64 & 1.10 \\
\hline Cohort 1965-69 & 0.99 \\
\hline Education low & 1 \\
\hline Education medium & 0.84 \\
\hline Education high & 0.81 \\
\hline Education other & 0.98 \\
\hline Not married before migration & 1 \\
\hline Married before migration & $1.34^{*}$ \\
\hline First language German/other & 1 \\
\hline First language Turkish & 0.90 \\
\hline Log Likelihood & -4126.43 \\
\hline Number of events & 737 \\
\hline Person months & 95193 \\
\hline
\end{tabular}

${ }^{* * *} p<0.001,{ }^{* *} p<0.01,{ }^{*} p<0.05$

Notes: German GGS 2005/06 (own calculations). 
Figure 9: Relative risks of having a higher order birth by duration of stay. Turkish respondents only. Both sexes combined.

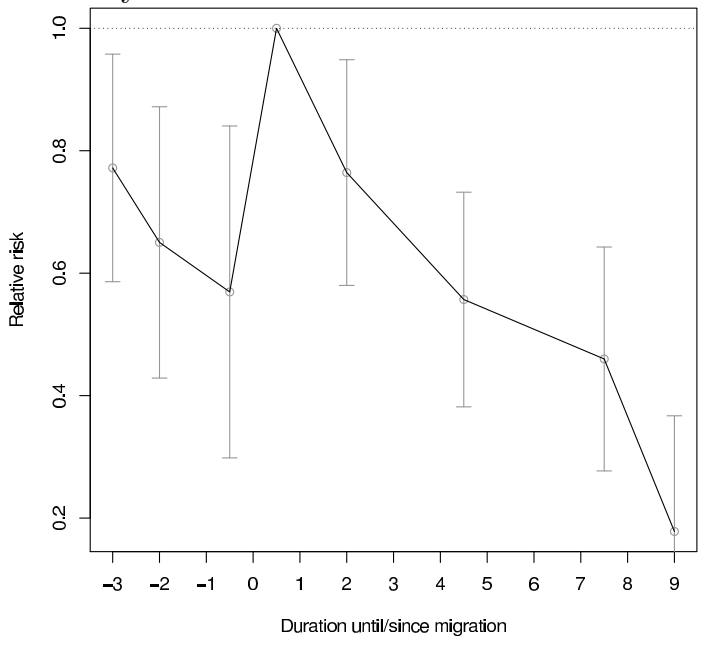

Notes: Controlled for time distance to last birth, parity, age at migration, sex, cohort, education, marital status and language use. The horizontal line at $y=1$ refers to the relative risk for Turks in the year of migration. German

GGS 2005/06 (own calculations).

Thus, it remains unclear whether being married before migration has a positive impact on fertility right after arrival. The positive impact of being married before migration is confirmed for higher order births. In Table 15 in the appendix the results for a similar model containing the age of the respondent instead of the age at migration are displayed. It shows that, with the exception of the migrants aged 35 and older, the fertility risks of the migrants do not differ significantly from those of the migrants aged 15-19.

Figure 9 reveals that higher order fertility among the Turkish migrants is lower during the years preceding migration than in the migration year. In addition, the elevation in the fertility risk immediately following the move is less pronounced for higher order than for first births.

Figure 10 illustrates the interaction between the duration of stay and the sex of the respondents for the transition to higher order births (the corresponding values can be seen in Table 16 in the appendix). During the three years preceding migration, there are differences by sex. While for the men the fertility risk is higher in this period than it is in the year of migration, the opposite is true for the women. The women have a low risk shortly before migration, but they experience a larger arrival effect than the men: the average woman's risk is about 1.5 times higher than it is for the average men. It therefore appears that only the risks during the first year after migration differ significantly between the men and women. This suggests that most of the Turkish couples migrated to Germany separately, which could explain the different fertility risks by duration 
Figure 10: Interaction between duration of stay and sex. Relative risks of having a higher order birth. Turkish respondents only.

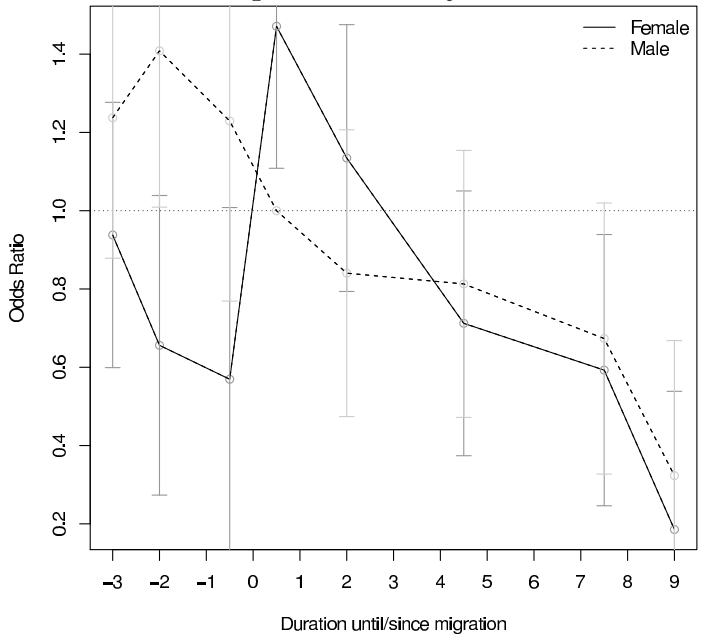

Notes: Controlled for time distance to last birth, parity, age at migration, sex, cohort, education, marital status and language use. The horizontal line at $y=1$ refers to the relative risk for Turks in the year of migration. German

GGS 2005/06 (own calculations).

of stay found for the men and women.

\section{Discussion}

In this study, the impact of the timing of migration on the fertility behavior of male and female Turkish migrants was examined. On the basis of multivariate discrete-time regression models, we find that the timing of migration is strongly associated with the fertility of Turkish migrants for the transition to the first birth, as well as for higher order births. Even after controlling for different individual factors, the duration of stay is shown to explain most of the differences between the Turks and their German counterparts. In general, we find a small negative anticipation effect of migration on Turkish migrant fertility. This applies particularly to women's transition to higher order births. Due to the very low fertility of the western Germans, who form our reference group, a clear statement on the existence of a negative anticipation effect is not possible. Furthermore, there is no evidence of a disruption of fertility in the years following migration. In fact, the opposite appears to be the case: an arrival effect was found, and fertility risks are particularly high in the years after the move. This applies to both the transition to the first birth as well as to the transition to higher order births, but the effect is stronger for first births. For the transition 
to the first birth, the arrival effect is even more distinct for the Turkish women than for the Turkish men. In sum, the risk of having a higher order birth is higher among the Turkish migrants than among the Germans.

Socialization theory suggests that the level of Turkish migrant fertility should be higher than that of the Germans, even with an increasing duration of stay. Adaptation theory, on the other hand, posits that migrant fertility will adapt to the German level over time. Our results show that the risk among the migrants of having a first child differ significantly from that of the Germans only during the initial years after migration, and that the risk even falls below the German level later on. For higher order births, the fertility risks are consistently higher among the Turkish migrants than among the Germans, but they start to decrease after more than nine years of stay in Germany. It is not clear whether this late decrease in fertility can be considered an adaptation, as it may also occur because of the advanced age of the migrants or because their fertility had been quite high after migration. Socialization theory further posits that there should be a positive relationship between the age at migration and the fertility level. This hypothesis has to be rejected as well. The age at migration influences fertility risks in a negative way. The older a Turkish migrant was when he or she migrated to Germany, the lower his or her risk of having a first or higher order child. An opposite effect may occur due to a postponement of fertility in response to migration. A migrant might postpone having children because migration is a stressful event, and new networks need to be set up, resources acquired, etc. If fertility is not recuperated, the postponement leads to lower fertility. In terms of selection theory, our results show that the migrants who were married before migration have a higher risk of having a higher order birth than the migrants who were not married before moving. This might be an indicator of the selectivity into a more family-oriented group. Unfortunately, we could not estimate an interaction between the duration of stay and the marital status. Thus, no statement can be made about the influence of marital status on the extent of the arrival effect.

Previous works on France and Catalonia (Devolder and Bueno, 2011; Toulemon, 2004) found distinctive arrival effects on migrant fertility. These effects are confirmed for the Turkish migrants in Germany. We further find that the fertility risk among the Turkish migrants decreases with increasing duration of stay, as was shown for France and Catalonia. The positive effect of being in a union and the large impact of the age at migration, particularly for those migrating in young adulthood ages, is also confirmed for the Turkish migrants. However, some of our findings differ from those for France and Catalonia. This might be because these studies examined all of the migrants together (Toulemon, 2004) or because the migrants were grouped by their continent of origin (Devolder and Bueno, 2011). Our work examines Turkish migrants in Germany, and thus focuses on one specific group of migrants. The strong anticipation effect of a low fertility risk in the years preceding the move shown by Devolder and Bueno (2011) is not evident for the Turkish migrants in Germany. For the Turks, hardly any anticipation is visible: their fertility decreases slightly before 
migration, but it never falls significantly below the German level. The small size of the Turkish anticipation effect might be related to the low German fertility level. In addition, the arrival effect of very high fertility right after migration is found to be even more extreme than it was in Catalonia and France. Most of the Turkish migrants probably came for the purposes of family reunion or family formation, which has a positive effect on the fertility risk during the years immediately following migration. The Turkish migrants apparently represent a specific migrant group in which migration and childbirth are highly interrelated. Furthermore, the Turkish migrants' risk of having a first child not only adapts to the German level with increasing duration of stay; it even falls below that level. This finding looks surprising, but can probably be explained by the very high arrival effects.

Most of the results on migrant fertility behavior in Germany are confirmed. Previous studies showed that among guest worker migrants, migration and childbirth tend to be closely related, not only for the transition to the first birth, but also to higher order births. Our results support those findings for Turkish migrants. Like previous studies on guest worker migrants, we did not detect any disruption of fertility immediately after migration for the specific group of Turkish migrants. On the contrary, a very clear arrival effect was found. Regarding the age at migration, our findings differ from previous findings. For Turkish migrants in Germany, fertility is highest for those migrants arriving during young adulthood. The later the migrants arrived, the lower their fertility.

This study adds to the previous findings in several ways. First, it offers detailed findings on male and female Turkish migrant fertility behavior in Germany. We found that the differences between the Turks and the native Germans in the transition to the first birth are mainly determined by the migrants' duration of stay. Furthermore, we emphasize the importance of the age at migration in explaining migrant fertility. It is not only associated with fertility risks (particularly for higher order births); it also has an impact on the age-specific fertility rates and on the total fertility rate. The highest fertility is found for the migrants who arrived in young adulthood. In sum, this work demonstrates the importance of a life course approach. A migrant's migration and fertility histories are closely related to each other. Unfortunately, it remains unclear to what extent migration and marriage are interrelated here. As migration is often understood as being an instrumental behavior (Mulder, 1992), we can assume there is a strong association between the two, especially for a selected sample like ours in which marriage migration plays an important role. It is, however, hard to disentangle the causality between migration, childbirth, and marriage. In our setting, we were able to show that fertility is particularly high in the years immediately after migration. But the extent to which migration is used as an instrument to achieve goals like marriage and the birth of a child (especially of the first child) remains unclear. Unfortunately, the GGS offers no information on the reasons for migration (like, for example, the German Socioeconomic Panel). Moreover, the sample size is too small to allow us to examine marriage in a more detailed way. To address this problem, different data sources are 
needed. However, while we are not able to separate out the effects of marriage and migration on migrant fertility, we were able to show that migration and fertility are closely interrelated for Turkish migrants in Germany, and that their fertility should not be examined without considering their migration history.

\section{References}

Abbasi-Shavazi, M. J. and P. McDonald (2002). A comparison of fertility patterns of European immigrants in Australia with those in the countries of origin. Genus, 53-76.

Alders, M. (2000). Cohort fertility of migrant women in the Netherlands. Developments in fertility of women born in Turkey, Morocco, Suriname, and the Netherlands Antilles and Aruba. Statistics Netherlands.

Andersson, G. (2004). Childbearing after Migration: Fertility Patterns of Foreign-born Women in Sweden. International Migration Review 38(2), 747774 .

Bade, K. J. (1992). Deutsche im Ausland, Fremde in Deutschland: Migration in Geschichte und Gegenwart. Mnchen: Beck.

Becker, G. S. (1981). A treatise on the family. Cambridge, MA: Harvard University Press.

Bledsoe, C. H. (2004). Reproduction at the Margins: Migration and Legitimacy in the New Europe. Demographic Research S3, 87-116.

Bledsoe, C. H., R. Houle, and P. Sow (2007). High fertility Gambians in low fertility Spain: The dynamics of child accumulation across transnational space. Demographic Research S5(12), 375-412.

Cygan-Rehm, K. (2011). Between here and there: Immigrant fertility patterns in Germany. BGPE Discussion Paper.

Devolder, D. and X. Bueno (2011). Effects of migration on fertility patterns for non-native women in Spain. European Population Conference, Stockholm. Draft Version 12/12/2011.

Dinkel, R. and U. Lebok (1997). The Fertility of Migrants Before and After Crossing the Border: The Ethnic German Population from the Former Soviet Union as a Case Study. International Migration 35(2), 253-270.

Eryurt, M. A. and I. Koç (2012). Internal Migration and Fertility in Turkey: Kaplan-Meier Survival Analysis. International Journal of Population Research, Article ID 329050. 
Goldstein, S. (1973). Interrelations between migration and fertility in Thailand. Demography 10(2), 225-241.

Goldstein, S. and A. Goldstein (1981). The impact of migration on fertility: An "own children" analysis for Thailand. Population Studies 35(2), 265-284.

Hervitz, H. M. (1985). Selectivity, adaptation, or disruption? A comparison of alternative hypotheses on the effects of migration on fertility: the case of Brazil. International Migration Review 19(2), 293-317.

Kahn, J. R. (1994). Immigrant and native fertility during the 1980s: Adaptation and expectations for the future. International Migration Review 28(3), 501519 .

Kreyenfeld, M., A. Hornung, K. Kubisch, and I. Jaschinski (2010). Fertility and union histories from German GGS data: some critical reflections. MPIDR Working Papers WP-2010-023, Max Planck Institute for Demographic Research, Rostock.

Kulu, H. (2005). Migration and fertility: Competing hypotheses re-examined. European Journal of Population / Revue européenne de Démographie 21(1), $51-87$.

Kulu, H. and A. González-Ferrer (2013). Family dynamics among immigrants and their descendants in europe: Current research and opportunities. FamiliesAndSocieties Working Paper Series.

Lee, B. S. (1992). The Influence of Rural-Urban Migration on Migrant's Fertility Behavior in Cameroon. International Migration Review 26 (4), 1416-1447.

Mayer, J. and R. T. Riphahn (1999, August). Fertility Assimilation of Immigrants: Evidence from Count Data Models. IZA Discussion Papers 52, Institute for the Study of Labor (IZA).

Milewski, N. (2007). First child of immigrant workers and their descendents in West Germany: interrelation of events, disruption, or adaptation? Demographic Research 17(29), 859-896.

Milewski, N. (2010). Immigrant fertility in West Germany: Is there a socialization effect in transitions to second and third births? European Journal of Population / Revue européenne de Démographie 26, 297-323.

Mulder, C. H. (1992). Internal migration of dutch birth cohorts: theoretical backgrounds and research activities.

Mulder, C. H. and M. Wagner (1993). Migration and marriage in the life course: a method for studying synchronized events. European Journal of Population / Revue européenne de Démographie 9, 55-76.

Münz, R., W. Seifert, and R. E. Ulrich (1999). Zuwanderung nach Deutschland: Strukturen, Wirkungen, Perspektiven. Frankfurt/Main: Campus. 
Rundquist, F.-M. and L. A. Brown (1989). Migrant fertility differentials in Ecuador. Geografiska annaler. Series B, Human geography 71(B)(2), 109123.

Sauer, L., K. Ruckdeschel, and R. Naderi (2012). Reliability of retrospective event histories within the German Generations and Gender Survey. BiB Working Paper 1/2012, Bundesinstitut für Bevölkerungsforschung, Wiesbaden.

Schmid, S. and M. Kohls (2009). Reproductive behaviour of migrant women in Germany: Data, patterns and determinants. Vienna Yearbook of Population Research 7(1), 39-61.

Singley, S. G. and N. S. Landale (1998). Incorporating Origin and Process in Migration-Fertility Frameworks: The Case of Puerto Rican Women. Social Forces 76 (4), 1437-1464.

Statistisches Bundesamt (2012). Bevölkerung mit Migrationshintergrund Ergebnisse des Mikrozensus 2011. Bevölkerung und Erwerbstätigkeit. Fachserie 1 Reihe 2.2, Wiesbaden.

Stephen, E. and F. Bean (1992). Assimilation, disruption and the fertility of Mexican origin women in the United States. International Migration Review 26(1), 67-88.

Toulemon, L. (2004). Fertility Among Immigrant Women: New Data, a New Approach. Population and Societies 400.

United Nations Population Division (2012). World Population Prospects: The 2012 Revision. 


\section{A Appendix}

Table 10: Sample construction. Number of respondents, childbirths and personmonths. Absolute numbers by sex and origin.

\begin{tabular}{lccccc}
\hline & \multicolumn{2}{c}{ Germans } & \multicolumn{2}{c}{ Turks } & Total \\
& Male & Female & Male & Female & \\
\hline GGS Total & 4610 & 5407 & 2129 & 1916 & 14062 \\
With non-missing year of birth & 4592 & 5375 & 2128 & 1905 & 14000 \\
Country of birth Turkey/Germany & 4027 & 4676 & 1576 & 1431 & 11710 \\
Living in West Germany & 3087 & 3513 & 1408 & 1355 & 9363 \\
With non-missing year of migration & 3087 & 3513 & 1372 & 1323 & 9295 \\
Without problems in birth histories + twins & 3077 & 3495 & 1358 & 1311 & 9241 \\
Birth cohort of respondent 1950-1969 & 1190 & 1554 & 580 & 597 & 3921 \\
\hline Total number of respondents & 1190 & 1554 & 580 & 597 & 3921 \\
\hline \hline First births & & & & \\
Number of person-months under risk (in million) & 21,492 & 23,898 & 1,225 & 824 & 47,440 \\
Number of births & 668 & 1243 & 782 & 845 & 3538 \\
\hline Higher order births & \multicolumn{5}{c}{} \\
Number of person-months under risk (in million) & 5,401 & 11,427 & 872 & 973 & 18,674 \\
Number of births & 668 & 1243 & 782 & 845 & 3538 \\
\hline
\end{tabular}

Notes: German GGS 2005/06, unweighted (own calculations). 
Figure 11: Event plot. Occurrences of first births by age at migration.

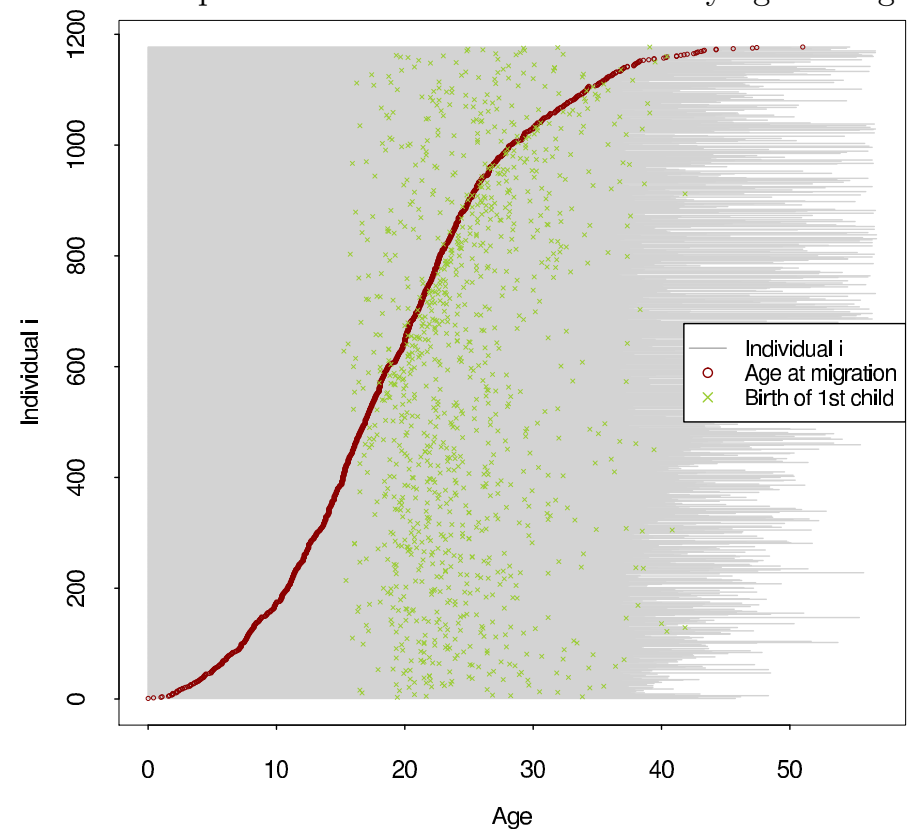

Notes: German GGS 2005/06, unweighted (own calculations). 
Figure 12: Event plot. Occurrences of first births by age at migration, separated by marital status before migration.

Married before migration

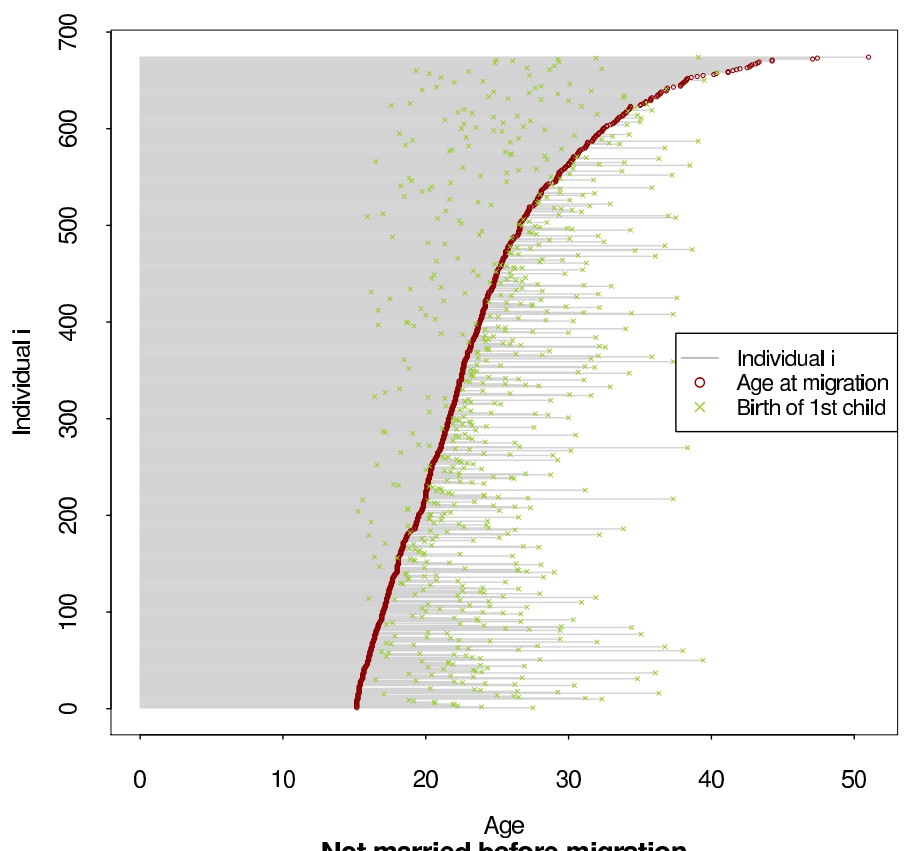

Not married before migration

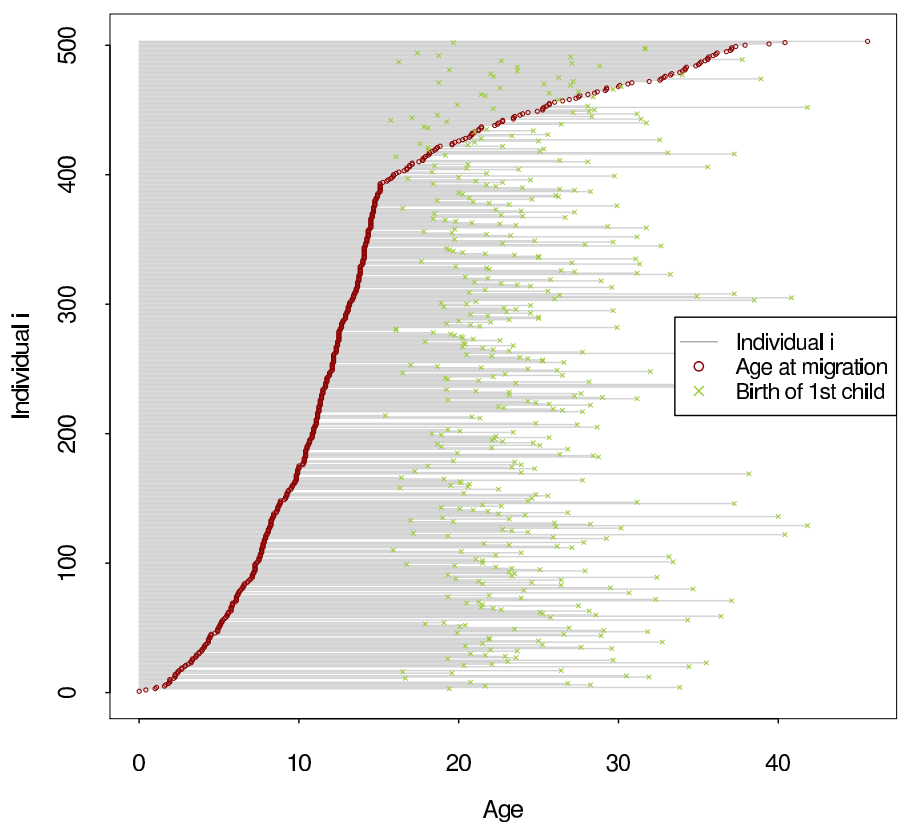

Notes: German GGS 2005/06, unweighted (own calculations). 
Table 11: Complementary log-log model. Relative risks of having a first birth. Interaction between duration of stay and sex. Turkish and German respondents.

\begin{tabular}{ll}
\hline & \multicolumn{1}{c}{ Model 1 } \\
\hline Germans, male & 1 \\
Duration -3, male & $0.83^{*}$ \\
Duration -2, male & $0.68^{*}$ \\
Duration -1, male & 0.58 \\
Duration 0, male & $3.23^{*}$ \\
Duration 1-2, male & $2.64^{*}$ \\
Duration 3-5, male & $1.39^{*}$ \\
Duration 6-8, male & $1.45^{*}$ \\
Duration 9+, male & $0.72^{*}$ \\
Germans, female & $1.22^{*}$ \\
Duration -3, female & $1.76^{*}$ \\
Duration -2, female & $0.99^{*}$ \\
Duration -1, female & $1.45^{*}$ \\
Duration 0, female & $4.71^{*}$ \\
Duration 1-2, female & $2.65^{*}$ \\
Duration 3-5, female & $0.93^{*}$ \\
Duration 6-8, female & 0.25 \\
Duration 9+, female & 0.28 \\
\hline Deviance & 52.605 \\
Pr(¿Chi) & $1.286 \mathrm{e}-08^{* * *}$ \\
\hline
\end{tabular}

${ }^{* * *} p<0.001,{ }^{* *} p<0.01,{ }^{*} p<0.05$

Notes: Controlled for age, cohort, education and union status. German GGS 2005/06, unweighted (own calculations). 
Table 12: Complementary log-log model. Relative risks of having a higher order birth. Interaction between duration of stay and sex. Turkish and German respondents.

\begin{tabular}{ll}
\hline & \multicolumn{1}{c}{ Model 1 } \\
\hline Germans, male & 1 \\
Duration -3, male & $2.07^{* * *}$ \\
Duration -2, male & $2.68^{* * *}$ \\
Duration -1, male & $2.43^{* *}$ \\
Duration 0, male & $1.95^{*}$ \\
Duration 1-2, male & $1.72^{* *}$ \\
Duration 3-5, male & $1.62^{* * *}$ \\
Duration 6-8, male & $1.80^{* * *}$ \\
Duration 9+, male & $1.48^{* *}$ \\
Germans, female & 1.02 \\
Duration -3, female & $1.65^{* * *}$ \\
Duration -2, female & 1.43 \\
Duration -1, female & 1.29 \\
Duration 0, female & $3.43^{* * *}$ \\
Duration 1-2, female & $2.71^{* * *}$ \\
Duration 3-5, female & $1.63^{* * *}$ \\
Duration 6-8, female & $1.69^{* * *}$ \\
Duration 9+, female & 0.92 \\
\hline Deviance & 58.202 \\
Pr(¿Chi) & $7.919 \mathrm{e}-09^{* * *}$ \\
\hline
\end{tabular}

${ }^{* * *} p<0.001,{ }^{* *} p<0.01,{ }^{*} p<0.05$

Notes: Controlled for time distance to last birth, parity, age, cohort, education and union status. German GGS 2005/06, unweighted (own calculations).

Table 13: Complementary log-log model. Relative risks of having a higher order birth by birth cohort and parity. Turkish and German respondents by origin and sex.

\begin{tabular}{lllll}
\hline & Turkish men & Turkish women & German men & German women \\
\hline Parity 1 & 1 & 1 & 1 & 1 \\
Parity 2 & $0.62^{* * *}$ & $0.61^{* * *}$ & $0.30^{* * *}$ & $0.39^{* * *}$ \\
Parity 3 & $0.34^{* * *}$ & $0.53^{* * *}$ & $0.61^{* *}$ & $0.42^{* * *}$ \\
Parity 4+ & $0.44^{* *}$ & 0.79 & 1.19 & $0.39^{* * *}$ \\
Cohort 1950-54 & 0.73 & 0.76 & 0.98 & $0.80^{*}$ \\
Cohort 1954-59 & 1 & 1 & 1 & 1 \\
Cohort 1960-64 & $1.51^{*}$ & 0.84 & 1.18 & $1.28^{* *}$ \\
Cohort 1965-69 & 1.17 & 0.83 & 1.24 & $1.41^{* * *}$ \\
\hline Log Likelihood & -15443.28 & -15417.10 & -15391.68 & -15373.67 \\
Number of events & 310 & 427 & 668 & 1243 \\
Person months & 36787 & 58406 & 130625 & 240330 \\
\hline
\end{tabular}

${ }^{* * *} p<0.001,{ }^{* *} p<0.01,{ }^{*} p<0.05$

Notes: Controlled for duration of stay (for Turkish respondents), time distance to last birth, age, sex, education and union status. German GGS 2005/06, unweighted (own calculations). 
Table 14: Complementary log-log model. Relative risks of having a first birth. Turkish respondents only.

\begin{tabular}{ll}
\hline & Model 3b \\
\hline Intercept & $0.0046^{* * *}$ \\
Duration of stay -3 & $0.25^{* * *}$ \\
Duration of stay -2 - 1 & $0.19^{* * *}$ \\
Duration of stay -1 & $0.24^{* * *}$ \\
Duration of stay 0 & 1 \\
Duration of stay 1-2 & $0.69^{*}$ \\
Duration of stay 3-5 & $0.33^{* * *}$ \\
Duration of stay 6-8 & $0.22^{* * *}$ \\
Duration of stay 9+ & $0.12^{* * *}$ \\
Age 15-19 & 1 \\
Age 20-24 & $2.21^{* * *}$ \\
Age 25-29 & $2.02^{* * *}$ \\
Age 30-34 & $1.56^{*}$ \\
Age 35+ & $0.56^{*}$ \\
Male & 1 \\
Female & 1.08 \\
Cohort 1950-54 & 0.88 \\
Cohort 1954-59 & 1 \\
Cohort 1960-64 & 0.95 \\
Cohort 1965-69 & 0.99 \\
Education low & 1 \\
Education medium & 1.09 \\
Education high & 0.92 \\
Education other & 1.07 \\
Not married before migration & 1 \\
Married before migration & 1.17 \\
First language German/other & 1 \\
First language Turkish & 1.03 \\
\hline Log Likelihood & -3096.33 \\
Number of events & 475 \\
Person months & 178884 \\
\hline &
\end{tabular}

${ }^{* * *} p<0.001,{ }^{* *} p<0.01,{ }^{*} p<0.05$

Notes: German GGS 2005/06, unweighted (own calculations). 
Table 15: Complementary log-log model. Relative risks of having a higher order birth. Turkish respondents only.

\begin{tabular}{|c|c|}
\hline & Model $4 \mathrm{~b}$ \\
\hline Intercept & $0.0169 * * *$ \\
\hline Duration of stay -3 & $0.60^{* *}$ \\
\hline Duration of stay $-2--1$ & $0.60^{*}$ \\
\hline Duration of stay -1 & $0.55^{*}$ \\
\hline Duration of stay 0 & 1 \\
\hline Duration of stay $1-2$ & 0.81 \\
\hline Duration of stay $3-5$ & $0.65^{*}$ \\
\hline Duration of stay $6-8$ & $0.59^{* *}$ \\
\hline Duration of stay $9+$ & $0.34^{* * *}$ \\
\hline Time distance to last birth 1 year & 1 \\
\hline Time distance to last birth 2 years & $2.15^{* * *}$ \\
\hline Time distance to last birth $3-4$ years & $2.04^{* * *}$ \\
\hline Time distance to last birth $5+$ years & $1.51 * * *$ \\
\hline Parity 1 & 1 \\
\hline Parity 2 & $0.65 * * *$ \\
\hline Parity 3 & $0.50 * * *$ \\
\hline Parity $4+$ & $0.71^{*}$ \\
\hline Age 15-19 & 1 \\
\hline Age $20-24$ & 1.05 \\
\hline Age $25-29$ & 0.89 \\
\hline Age $30-34$ & 0.73 \\
\hline Age $35+$ & $0.40^{* *}$ \\
\hline Male & 1 \\
\hline Female & $0.79 * *$ \\
\hline Cohort 1950-54 & $0.79^{*}$ \\
\hline Cohort 1954-59 & 1 \\
\hline Cohort 1960-64 & 1.07 \\
\hline Cohort 1965-69 & 0.95 \\
\hline Education low & 1 \\
\hline Education medium & 0.86 \\
\hline Education high & 0.79 \\
\hline Education other & 0.96 \\
\hline Not married before migration & 1 \\
\hline Married before migration & $1.36^{*}$ \\
\hline First language German/other & 1 \\
\hline First language Turkish & 0.89 \\
\hline Log Likelihood & -4111.05 \\
\hline Number of events & 737 \\
\hline Person months & 95193 \\
\hline
\end{tabular}

*** $p<0.001, * * p<0.01, * p<0.05$

Notes: German GGS 2005/06, unweighted (own calculations). 
Table 16: Complementary log-log model. Relative risks of having a higher order birth. Interaction between duration of stay and sex. Turkish respondents only.

\begin{tabular}{ll}
\hline & Model 4a \\
\hline Duration -3, male & 1.24 \\
Duration -2, male & 1.41 \\
Duration -1, male & 1.23 \\
Duration 0, male & 1 \\
Duration 1-2, male & 0.84 \\
Duration 3-5, male & 0.81 \\
Duration 6-8, male & 0.67 \\
Duration 9+, male & $0.32^{* *}$ \\
Duration -3, female & 0.94 \\
Duration -2, female & 0.66 \\
Duration -1, female & 0.57 \\
Duration 0, female & 1.47 \\
Duration 1-2, female & 1.13 \\
Duration 3-5, female & 0.71 \\
Duration 6-8, female & 0.59 \\
Duration 9+, female & $0.19^{* * *}$ \\
\hline Deviance & 17.738 \\
Pr(¿Chi) & $0.01321^{*}$ \\
\hline$* * *<0.001, * *$
\end{tabular}

${ }^{* * *} p<0.001,{ }^{* *} p<0.01,{ }^{*} p<0.05$

Notes: Controlled for distance to previous birth, parity, age at migration, cohort, education, marital status and first language. German GGS 2005/06 (own calculations). 